\title{
A Bio-Inspired Mind Map to Assist in Concept Generation for Wall Climbing Systems: Development, Assessment, and Resulting Prototypes
}

\section{Dr. Daniel D. Jensen, U.S. Air Force Academy}

Dr. Dan Jensen is a Professor of Engineering Mechanics at the U.S. Air Force Academy where he has been since 1997. He received his B.S. (Mechanical Engineering), M.S. (Applied Mechanics) and Ph.D. (Aerospace Engineering Science) from the University of Colorado at Boulder. He has worked for Texas Instruments, Lockheed Martin, NASA, University of the Pacific, Lawrence Berkeley National Lab and MSC Software Corp. His research includes design of Micro Air Vehicles, development of innovative design methodologies and enhancement of engineering education. Dr Jensen has authored over 100 refereed papers and has been awarded over $\$ 4$ million of research grants.

\section{Dr. Kristin L. Wood, Singapore University of Technology and Design (SUTD)}

Dr. Kristin L. Wood is currently a Professor and Head of Pillar, Engineering and Product Development (EPD), and Co-Director of the SUTD-MIT International Design Center (IDC) at the Singapore University of Technology and Design (SUTD). Dr. Wood completed his M.S. and Ph.D. degrees in the Division of Engineering and Applied Science at the California Institute of Technology, where he was an AT\&T Bell Laboratories Ph.D. Scholar. Dr. Wood joined the faculty at the University of Texas in September 1989 and established a computational and experimental laboratory for research in engineering design and manufacturing, in addition to a teaching laboratory for prototyping, reverse engineering measurements, and testing. During his academic career, Dr. Wood was a Distinguished Visiting Professor at the United States Air Force Academy. Through 2011, Dr. Wood was a Professor of Mechanical Engineering, Design \& Manufacturing Division at The University of Texas at Austin. He was a National Science Foundation Young Investigator, the "Cullen Trust for Higher Education Endowed Professor in Engineering," "University Distinguished Teaching Professor," and the Director of the Manufacturing and Design Laboratory (MaDLab) and MORPH Laboratory. Dr. Wood has published more than 400 refereed articles and books; has received more than 70 national and international awards in design, research, and education; and is currently a Fellow of the American Society of Mechanical Engineers.

Aaron P Bauer, United States Air Force Academy

Mr. Blake Perez, Singapore University of Technology and Design

Milton Doria, United States Air Force Academy

Dr. Michael Lawrence Anderson P.E., United States Air Force

Lt Col Mike Anderson is Associate Professor and Deputy Department Head of Engineering Mechanics, US Air Force Academy. He has been researching autonomous systems for fourteen years, authoring several papers relevant to the field including design of terrestrial and aerial robots, energy efficiency and perching for small UAS, and flight control of Micro Air Vehicles (MAV). Lt Col Anderson has worked as an F-16 flight control actuation systems engineer at Hill Air Force Base, Utah and researched design and control of quadruped robots. Lt Col Anderson earned his $\mathrm{PhD}$ in Aeronautical Engineering from the Air Force Institute of Technology in 2011 where he performed pioneering research in the design and control of flapping wing MAVs. From 2011-2014 he served in the Air Force Research Laboratory's Munitions Directorate (AFRL/RW) where he led research in GPS-denied navigation for multi-agent autonomous systems. Lt Col Anderson is a registered Professional Engineer and a Associate Fellow of the American Institute for Aeronautics and Astronautics, where he serves on their Unmanned Systems Program Committee. His research at the Academy focuses on innovative design methodologies applied to UAV problems

Luke Jensen, CREO 


\title{
A Bio-Inspired Mind Map to Assist in Concept Generation with Application to Wall-Climbing Robotic Systems
}

\begin{abstract}
The ability to climb walls (or any vertical surface) is a tremendously useful capability for both biological systems and human-made systems. Biological systems can use this climbing capability to protect themselves from ground-based enemies or to obtain an advantageous position for surveillance. Human-made systems find similar advantages particularly if one of their core functions is gathering intelligence, surveillance or reconnaissance (ISR). Climbing vertical surfaces is a difficult task as evidenced by the relatively few mechanical systems that have climbing capabilities. Biological systems use a wide variety of methods to climb. In this work, we show how a mind map, which displays numerous ways that biological systems climb, can be used to develop concepts and prototypes for mechanical systems that climb. In particular, a mind map that contains eleven different examples of how biological systems climb is used in the concept generation or ideation step in a design process to produce numerous ideas for mechanical climbing systems. The mind map contains both pictorial and text information on the climbing capability for the biological entity. In addition, a mind map that provides ways that additive manufacturing might enhance the design was developed and used. After use of the mind maps for ideation, a "down-select" process was used on the set of concepts resulting in the selection of two concepts for prototyping and testing. One concept involved attaching a ladderlike structure to the wall and creating a robot with ladder climbing abilities. The second concept implemented a projectile that was launched and adhered to the wall. The projectile had an attached tether. A robot then used the tether to winch itself up the wall. The mind maps were found to be effective in assisting the development of concepts for wall-climbing capability and the resulting two prototypes showed definitive feasibility of the two wall-climbing concepts.
\end{abstract}

\section{INTRODUCTION}

The capability for a robotic system to climb walls has many advantages. In addition to providing enhanced ability to gather intelligence, surveillance and reconnaissance (ISR) information, many times there is a need for the robotic system to move from level to level inside a structure. Robotic systems that fly can, of course, accomplish this "wall-climbing" capability. However, flying systems have at least two significant drawbacks. First, they most often consume far more power than a comparable ground based system. Secondly, they are normally more difficult to control than a ground based system. Some systems that combine ground based manoeuvring with some flight capability have been developed. While these systems combine some of the advantageous capabilities of both ground and flight systems, they still do not have the capability to climb and then stick on a wall. 
Researchers have developed numerous systems that have some ability to climb walls. Further discussion of these systems is detailed in the next section. However, most of these systems (at least the ones that use Van der Waals forces to adhere to the wall) lack capability to climb walls with varied profiles and textures. Systems that use suction for the adherence overcome some of these limitations. The downside of these suction based systems tend to be heavy and that they require significant power.

Ideation is the step in the design process during which the design team develops multiple concepts to meet a set of customer needs. Ideation methods assist in this step by providing techniques to develop greater quantity, quality and novelty in the potential solution space of ideas [12-14,21-22]. Use of ideation methods has been shown to enhance the quantity, quality and novelty of the potential solution space when compared to the sole use of traditional brainstorming [1].

Design by analogy (DBA) is an ideation method that attempts to use analogies to inspire new ideas. DBA use has seen significant growth in recent years [16-20]. While there are many specific techniques that use analogies to inspire ideas (and more details are provided in this area in subsequent sections), the use of biological systems as analogies is one of the main subcategories of DBA [9]. It appears, however, that simply asking designers to think of biological systems as analogies for solving a design problem is rarely productive. This is likely because the biological realm is so vast and most designers do not have significant training in biological systems. Therefore, a method that assists the designer in using biological analogies could be helpful.

Mind maps are a method to organize data graphically and sometimes pictorially and using text. Main maps can be used to show relationships between different concepts and can also show categories of concepts. The use of mind maps can significantly enhance ideation [2-3, 23]. Mind maps can be used to enhance the bio-inspired DBA process. Biological examples with both text and pictorial representations can be used in a mind map to inspire ideas for certain capabilities. In particular, we have developed two mind maps to enhance the design of wallclimbing systems. The first mind map shows examples of biological systems with wall-climbing capabilities and the second provides insight into how additive manufacturing might enhance the design process.

\section{RESEARCH STRATEGY}

This work has three main objectives:

1) Development and assessment of design methods for bio-inspired systems

2) Development and assessment of design methods to integrate additive manufacturing into a design process 
3) Development of prototypes that show capabilities for wall-climbing

These objectives lead to the following three research questions:

1) Does the use of a mind map that presents bio-inspired analogies enhance the ideation process?

2) Does the use of a mind map that presents opportunities for use of additive manufacturing enhance the ideation process?

3) Does the use of both mind maps lead to the development of new robotic systems with wall-climbing capabilities?

\section{BACKGROUND WORK}

Related work in the field of wall-climbing robots has produced several different strategies including wheels, treads, legs, and other attachment mechanisms. One wheel/tread platform utilizes a series chain on two tracked wheels on which 24 suction pads are installed to facilitate continuous locomotive motion with a high climbing speed of $15 \mathrm{~m} / \mathrm{min}$. While each tracked wheel rotates, the suction pads that attach to the vertical plane are activated in sequence by specially designed mechanical valves [31]. There are several different kinds of track-wheel robots: a high-speed vertical climbing robot, a flexible caterpillar robot, and a multi-linked climbing robot. The high-speed vertical climbing robot uses suction pads to be attached on walls, and has an advantage of high climbing speed of $14 \mathrm{~m} / \mathrm{min}$. The flexible caterpillar robot can configure its body shape according to external structure condition by using flexible joints. The robot is attached to the wall using segmented magnets. The robot can perform 90 degrees wallto-wall internal transition without a complex controller. The multi-linked climbing robot is composed of three main bodies that are controlled by kinematic relations. By using the three bodies, the robot can perform 90 degrees wall-to-wall internal transition. The adhesion mechanism is same as the high-speed vertical climbing robot (suction pad) [34].

While these wheels/treads platforms can be effective to an extent, work in the field of legged climbing robots has shown great potential. With minimal adjustments, legs can be used for both terrestrial locomotion and wall-climbing, with the capability of retraction for flight. Research in this area has shown results of robots' ability to climb a diverse number of surfaces. Quasi-static climbing-ignoring the system's momentum in favor of slow climbing with a focus on attachment mechanisms - has been a noticeable trend in previous legged climbing platforms. Research done on attachment mechanisms includes sticky treads [24], suction [27], grasping discrete footholds [25], as well as the use of electromagnets [26]. RiSE robots [28] are such a platform; while capable of climbing many different surfaces, their speeds are no match for their biological equivalents, i.e. geckos [8].

However, dynamic climbing robots — which are capable of actively managing total system energy while running on vertical surfaces-have the potential to approach the climbing speeds 
exhibited in nature. Dickson and Clark use dynamic scaling relationships to compare the climbing velocities of wall-climbing robots as opposed to their biological counterparts [30], indicating that some of these robotic systems approach the capabilities of their biological counterparts.

However, as has been previously stated, when scaled to the same mass, the majority of wallclimbing robots are significantly slower than comparable biological systems. However, the bipedal dynamic climbing system, Dynoclimber, may present a solution in reducing this disparity. Inspired by the climbing dynamics of the cockroach, Blaberus discoidalis, and the gecko, Hemidactylus garnoti [33], Dynoclimber utilizes the Full-Goldman (FG) [35] template of scansorial locomotion, which approximates the rapid vertical climbing seen in cockroaches and geckos using two virtual legs [32].

\section{DEVELOPMENT OF DESIGN METHODS}

A new bio-inspired design method for wall-climbing systems has been developed. This method is intended to enhance the concept generation or ideation phase of a design project. Effective ideation is often seen as the key step in the design process for enhancing innovation [1]. Concept generation methods can be broken into two categories; either "Intuitive" or "Directed". Directed methods are step-by-step, logical methods to produce ideas. Intuitive methods can be implemented either individually or in a group and are more open-ended and fluid. Shah [36] provides a list of some of the different techniques in these two categories as seen in Figure 1.

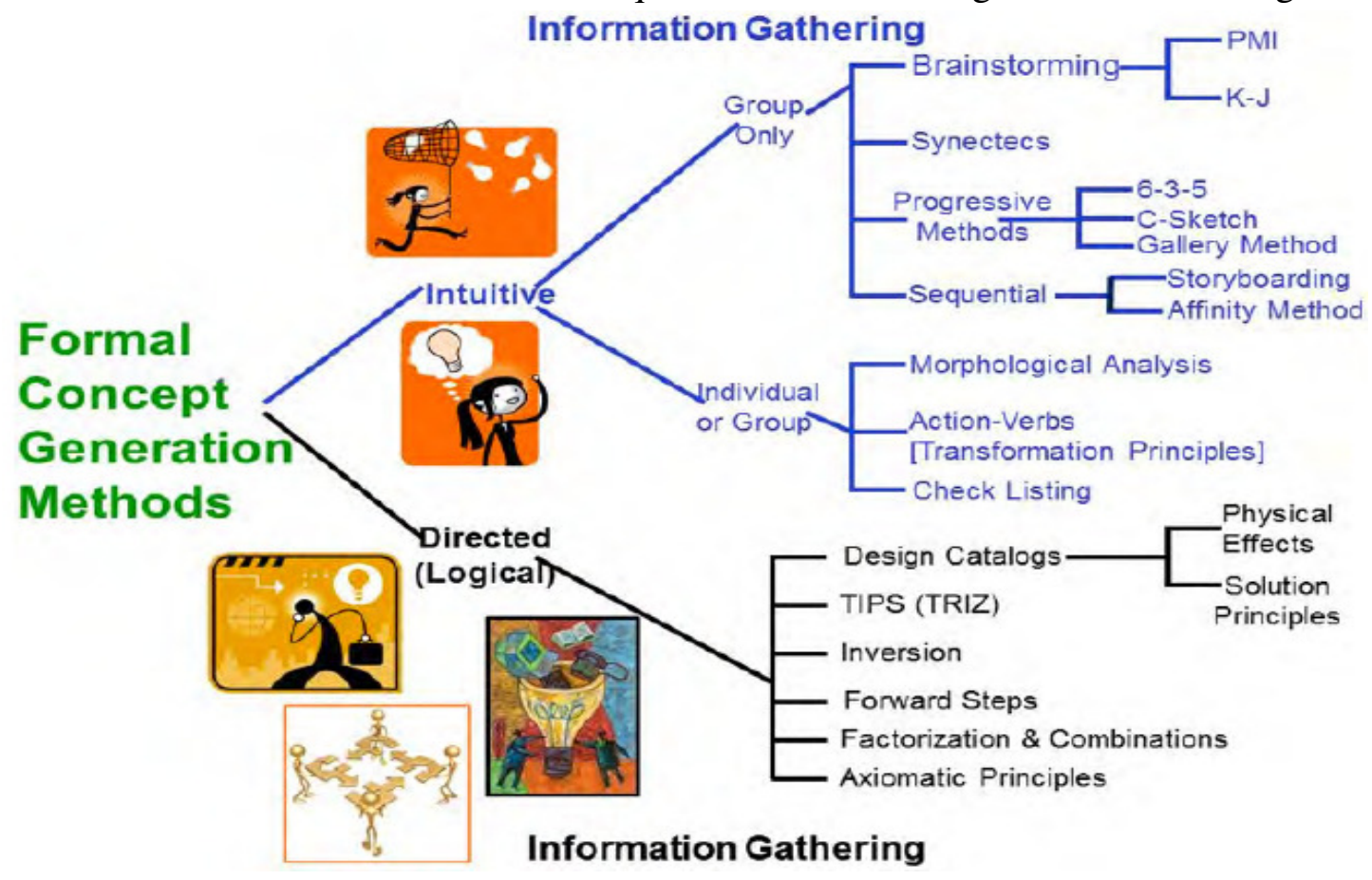

Figure 1 - Typical Ideation Methods [1, 36] 
Design by analogy (DBA) is an ideation technique that uses analogies to inspire concept generation. DBA can take many forms [20]. For example, analogies can be developed from products that have similarities to the proposed design, possibly sharing a similar functional description or core set of customer needs. Analogies can also be developed using grammatical similarities with key functions or customer needs for the proposed product [4]. Grammaticalbased analogies can be organized using word trees as seen in Figure 2 [4]. In this method, a key customer need of key function forms the "source word". This source word is input into the WordNet program created at Princeton [37]. The program outputs both troponyms (synonyms that are more specific) and hypernyms (synonyms that are more general). The troponyms and hypernyms can be used to form the word tree [38]. Normally, hypernyms are placed above the source word and troponyms are placed below as can be seen in the Figure 2.

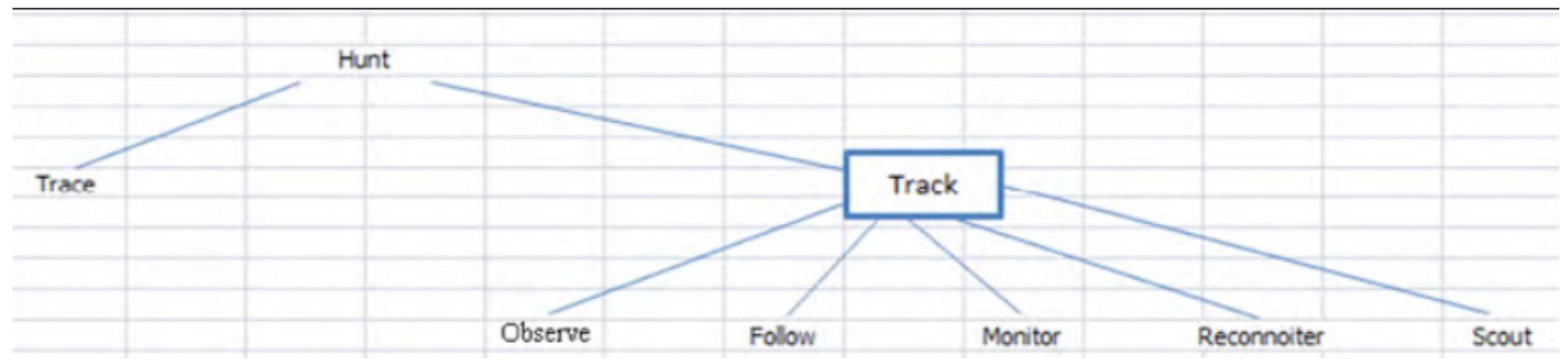

Figure 2 - Example of a Portion of a Word Tree for Design by Analogy $[1,38]$

Another method for accomplishing DBA is to seek bio-inspired analogies which inspire ideation $[6,9,15-19]$. One potential difficulty in employing bio-inspired DBA is that the biological realm is so vast and diverse that designers can have difficulty imagining biological entities that could serve as helpful analogies for their specific design. This is especially true if the designer does not have extensive training in biology. Hence, a method that could provide some of these biological analogies could be beneficial.

Mind maps are a technique to organize data that shows relationships between the data entries graphically. The word tree shown in Figure 2 could be considered one type of mind map. Research shows that in many cases the use of mind maps enhances ideation processes [2,6-7]. Mind maps can be used in other manners to assist in the ideation process. Figure 3 shows one example where a mind map is used to represent a possible design for a system that transforms between a motorcycle and a ATV. The initial nodes are three ways the system could transform (Expand/Collapse, Fuse/Divide or Expose/Cover) and the outer nodes are actual embodiment ideas for the system. 


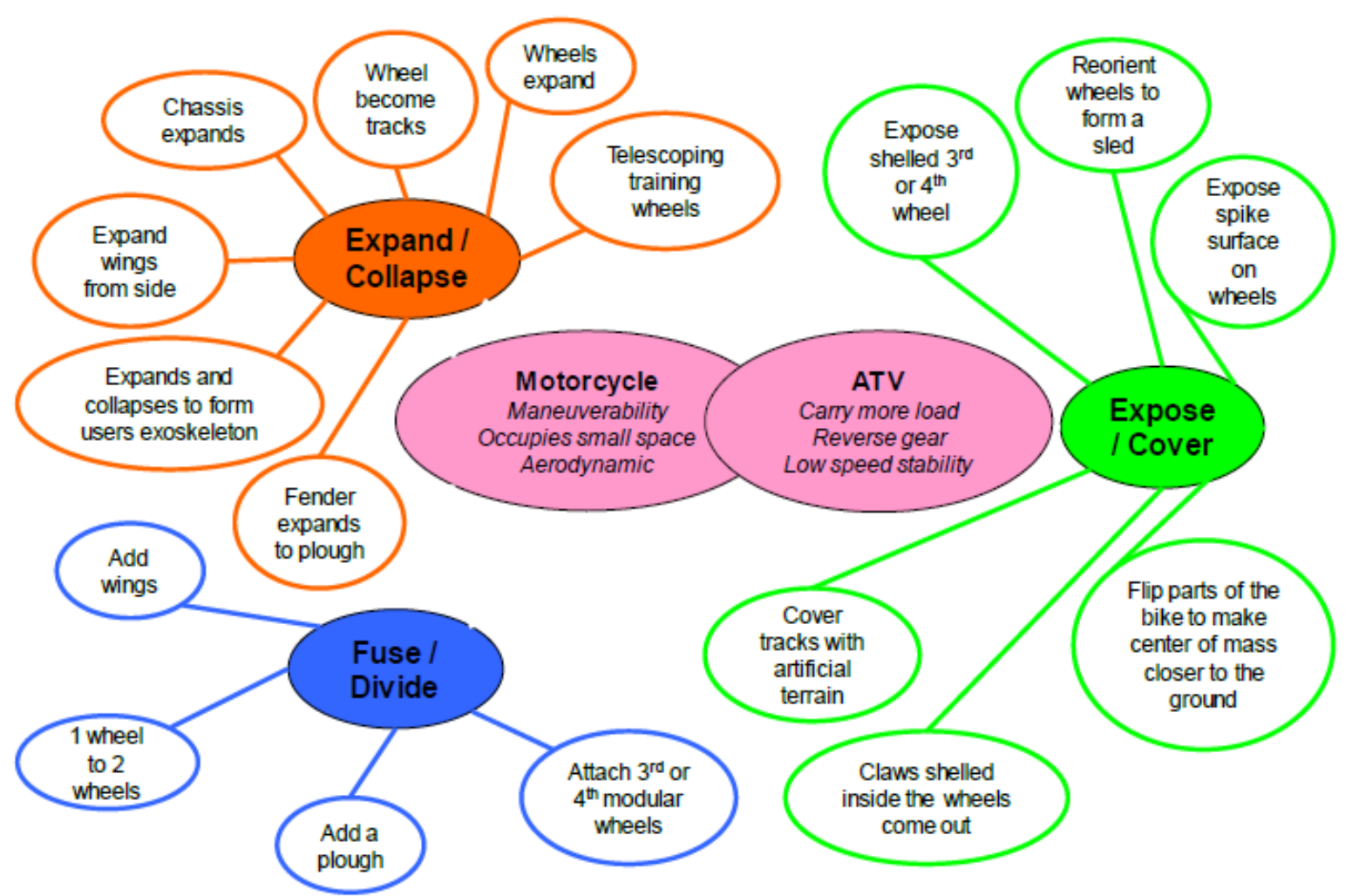

Figure 3 - Example of a Mind Map [1]

We have developed mind maps that present biological examples for accomplishing specific key functions [3]. Specifically, we have developed a bio-inspired mind map for wall-climbing capability. The mind map contains numerous examples of biological systems that accomplish this feat. Both representative pictures and corresponding textual descriptions are included. Our assessment of these methods indicates that the use of the bio-inspired mind maps enhances the DBA-focused ideation process by helping designers produce increased quantity, quality and novelty when compared to a DBA process that does not use the mind map [3].

Biological entities have a very diverse set of tactics for accomplishing climbing. In our efforts to enhance ideation for the climbing function, we broke the problem into two sub-problems: attaching to the wall and the locomotion up the wall. Because of the bio-inspired focus of this work, one of the primary sources of information was AskNature.Org. After gathering information regarding the problem, two separate mind maps were created to assist in the ideation section; one for climbing and one to assist in developing ideas on how additive manufacturing (AM) might enhance the design. Ideation was accomplished through a modified 6-3-5 (sometimes called C-Sketch) method where designers individually ideate for a period of time recording their ideas on the mind map $[8,10]$. Then, they pass their ideation paper to the colleague next to them and receive the paper from another colleague. They add to/modify/challenge/clarify their colleagues' ideas and then pass and receive again. This is done 
without interaction between the designers until each has had the opportunity to interact with all the other designers' original papers. After ideation, the "Real-Win-Worth" method [11] is used to narrow down the possible ideas and combine these ideas.

As mentioned above, two mind maps were constructed. One was to enhance the development of bio-inspired wall-climbing systems and the other was to investigate is additive manufacturing might improve this specific design process. This was done to facilitate the process and increase the net quantity of ideas formed - as research has shown that quantity leads to quality and novelty [22]. The mind maps are shown in Figures 4 and 5. 


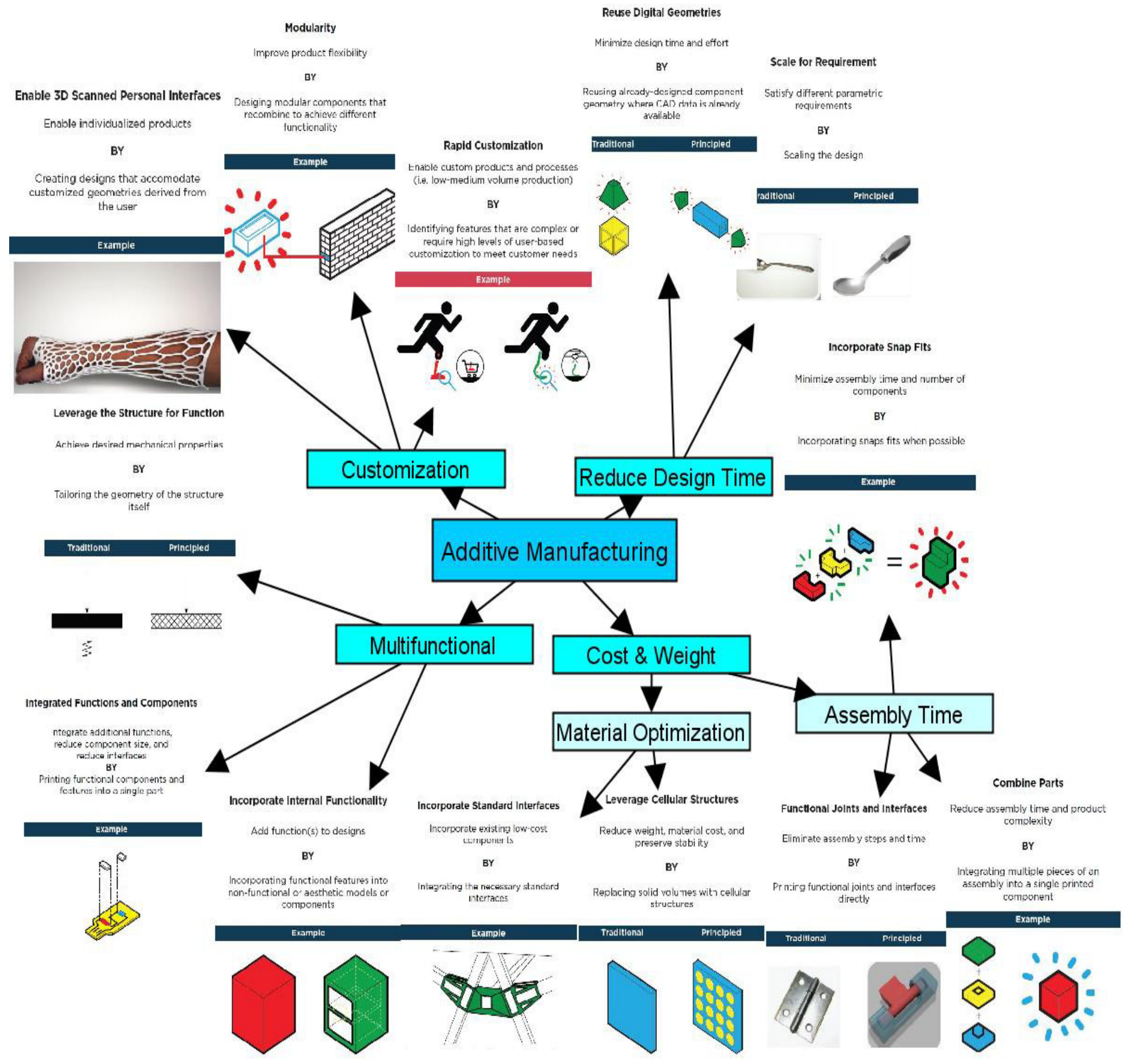

Figure 4 - Additive Manufacturing Mind Map 


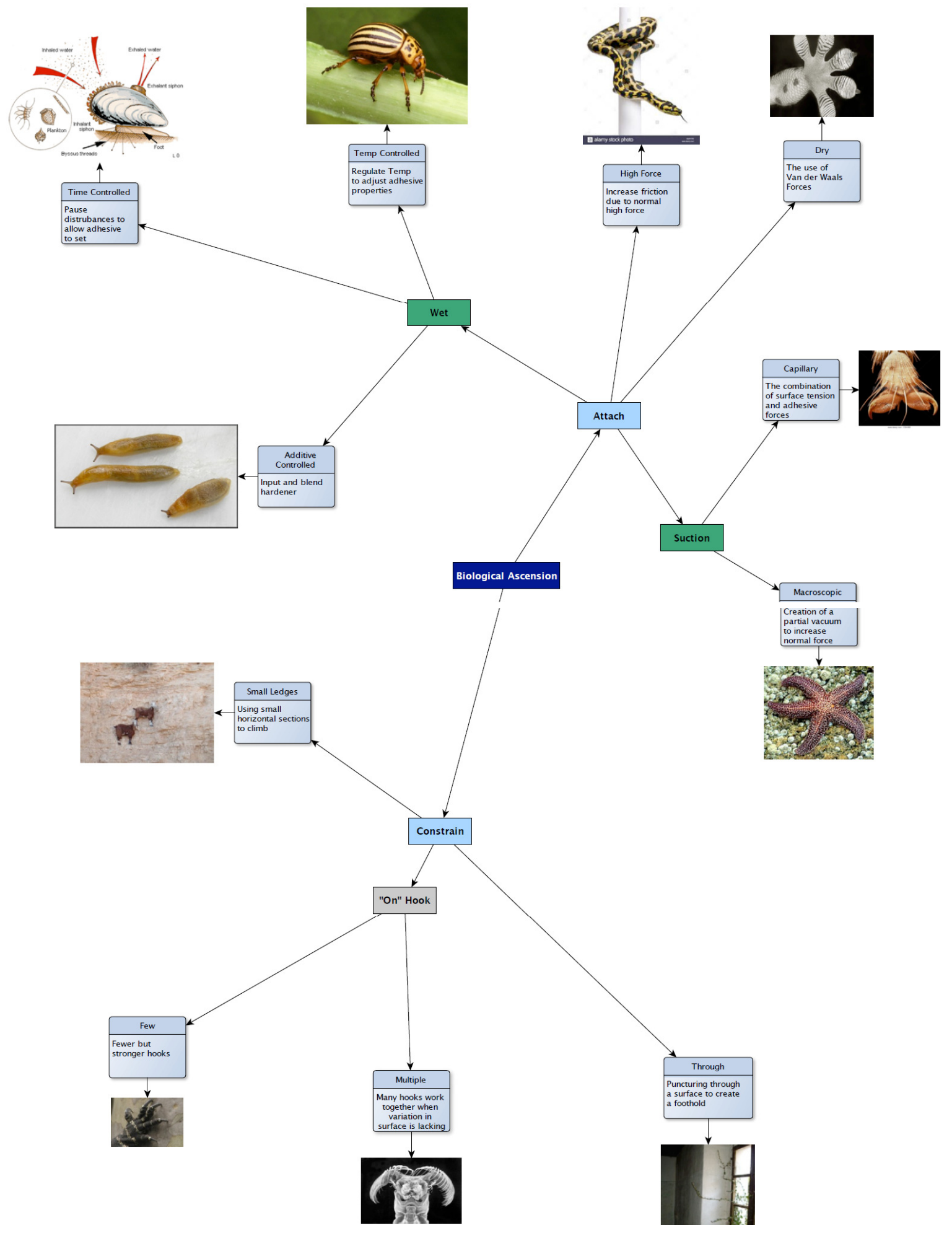

Figure 5 - Bio-Inspired Climbing Mind Map 


\section{ASSESSMENT OF THE DESIGN METHODS}

As can be seen in the previous two figures, the mind maps focused on biological ascension (climbing) and additive manufacturing (AM). Using these mind maps as a primary source of inspiration for developing ideas for the project, two sessions of a modified version of the 6-3-5 were conducted as described above. For each individual session, four individuals were handed identical mind maps, first of the biological ascension and then the AM focus. These individuals were given five minutes to annotate their ideas on the mind maps before passing it off to the next person. This was done until each individual had seen the four mind maps (their own and those of their three colleagues).

After the two ideation sessions, the ideas were collected and categorized. Using the Real-Win-Worth method [11], the number of possible ideas was decreased to 15. During the "real" portion, ideas that were not feasible were discarded. For the "win" section, those that were considered not to be novel were discarded. For the worth part, ideas were discarded that could not be pursued due to limitations such as time, supplies, and resources. An example of the mind map after use in the 6-3-5 session is shown in Figure 6. Prototyping of the two "downselected" designs is described below. 


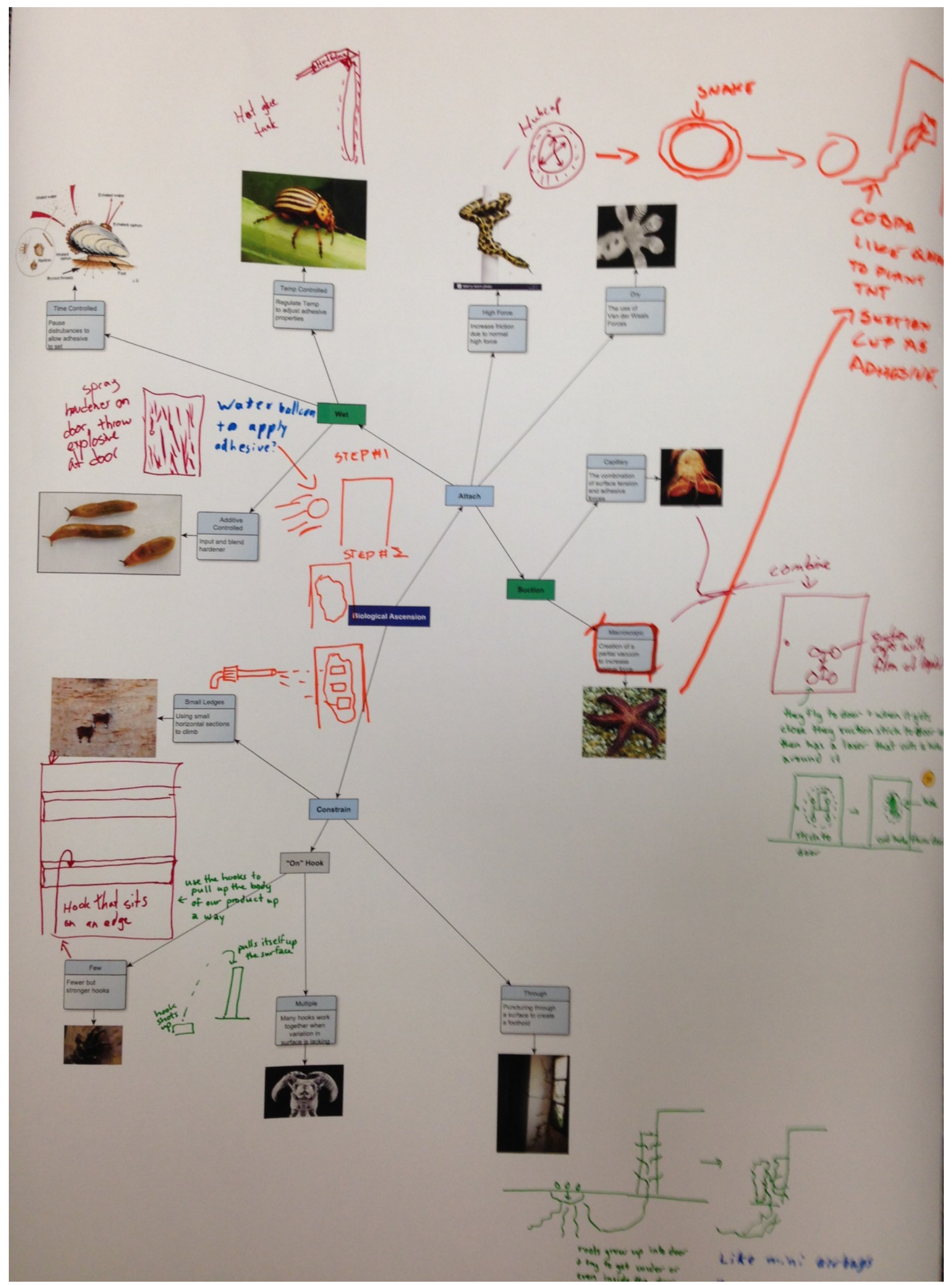

Figure 6 - Example of Ideas from the Bio-Inspired Climbing Mind Map 
Assessment of the methods includes quantitative evaluation of the number of concepts generated as well as qualitative feedback from the users. Normally, when a design team is given two sequential attempts to generate ideas, the number of ideas generated in the second attempt will decrease simply because they have already generated numerous concepts. In this case, however, the number of ideas generated using the mind map was either very close to the same, or for some design teams, even increased. This is obviously seen as a positive result.

Four different industrial design groups (two from industry and two from government) as well as numerous student design teams were part of our bio-inspired mind map assessment. The industrial and government groups that used bio-inspired mind maps found the method to be very productive. Some of the groups that have evaluated our mind maps have used the mind maps in a modified 6-3-5 or C-Sketch manner. Specifically, they spent 5 minutes individually using the mind map to create ideas and then they gave their paper to a colleague who reacted to these ideas by adding or modifying the ideas, or in some cases creating addition, new ideas. This method avoids some of the pitfalls of group ideation methods. This scheme of was done a number of times and in all cases designers were still able to develop ideas even when they were viewing the $3^{\text {rd }}$ colleague's mind map.

Results from the two different methods (climbing and AM) were very similar. In addition, the designers were asked for their qualitative assessment of the tools. Feedback was very positive overall. Specifically, designers stated that the mind maps were, in general, easy to understand and definitely helped them generate ideas that they would not have developed without the mind map. In addition, the mind maps led to the development of the prototypes below, which is seen as positive assessment as well.

One of the main reasons for positive feedback when using a mind map was because of the ability to pull from metaphorical shelf of knowledge. The participants reported that they did not have to think very long or hard in order to make a connection between biological systems and a wall-climbing robot. In addition, the AM mind map introduced designers to the possibilities that are capable with additive manufacturing; many of these were unfamiliar to them. This allowed for a new breadth of ways to construct ideas.

Users have also provided suggestions for improvements in the mind maps. One suggestion was to investigate what the optimal set of bio examples might be. Another idea was to provide additional resources for each example; but not on the initial mind map as the level of information on the mind map is seen to be about the maximum that can be absorbed. This second suggestion (provide additional info) was applicable to both the bio and AM mind maps. Finally, for both mind maps, designers suggested that we develop a web-based system for the mind maps that could allow for easy access to the additional information and even to the source documents for that information.

\section{PROTOTYPES}

We have developed two new prototypes that demonstrate capabilities that are relevant to the project. These systems include wall-climbing capabilities through:

1) Changing the characteristics of the wall (i.e. extension of a ladder-like system that the ISR system can then climb)

2) Using the extendable winching capabilities (i.e. attachment of an anchor on the wall that allows the ISR system to pull itself up the wall) 
3) Providing adherence capabilities (adhesion capabilities for short turn "stick" followed by long term "stick" that can withstand normal, shear and creep stresses).

Items 2) and 3) above combine into a system that has the capabilities to maneuver in a room, aim a projectile, shoot a projectile that adheres to a wall and use that projectile as an anchor for pulling an ISR system up a wall. All these designs were created using the design methods detailed above.

\subsection{Prototype \#1 - Ladder}

The first prototype was designed based on the idea that wall texture would not matter if the robot climbed a ladder instead of the wall. This ladder concept begins with a rolled up 3-D printed ladder, extends it up a wall, climbs it using a robot with tank treads that also have 3-D printed hooks, and reels the ladder back in when the robot gets to the top of the wall. The initial prototype was constructed using popsicle sticks and hot glue on a premade tank body. This demonstrated that climbing power would not be an issue. The second prototype was constructed with sections of wood to try to overcome obstacles seen previously. This prototype was able to get on and climb a vertical ladder with ease. Finally, a robot with multiple moving pieces was printed in order to see if the ladder could be extended up a wall, which it successfully accomplished.

This design demonstrated that extending a climbable object (ladder) up a surface and climbing that object is feasible and provides wall-climbing capability. However, this concept has limitations in its current embodiment if it were to be employed on the small robot system. Below, we explicitly define these limitations.

The first issue is that the ladder would need to be both extremely light and very stiff. This combination of material properties is not unachievable with the type of AM material we were using. However, a folded or rolled composite ladder would likely meet these design requirements. The second limitation is that the ladder needs to be packed tightly to fit on a small robotic system. By rolling it around a track, the size was decreased but additional volume reduction would likely be needed. Third, the ladder design we used only facilitates climbing up to a certain height determined by the length of the ladder. The ladder's length is obviously related to its weight and structural stiffness as well as its volume. The design progression for the climbing robot is shown in Figure 7 . The progression of the ladder design can be seen in Figure 8.

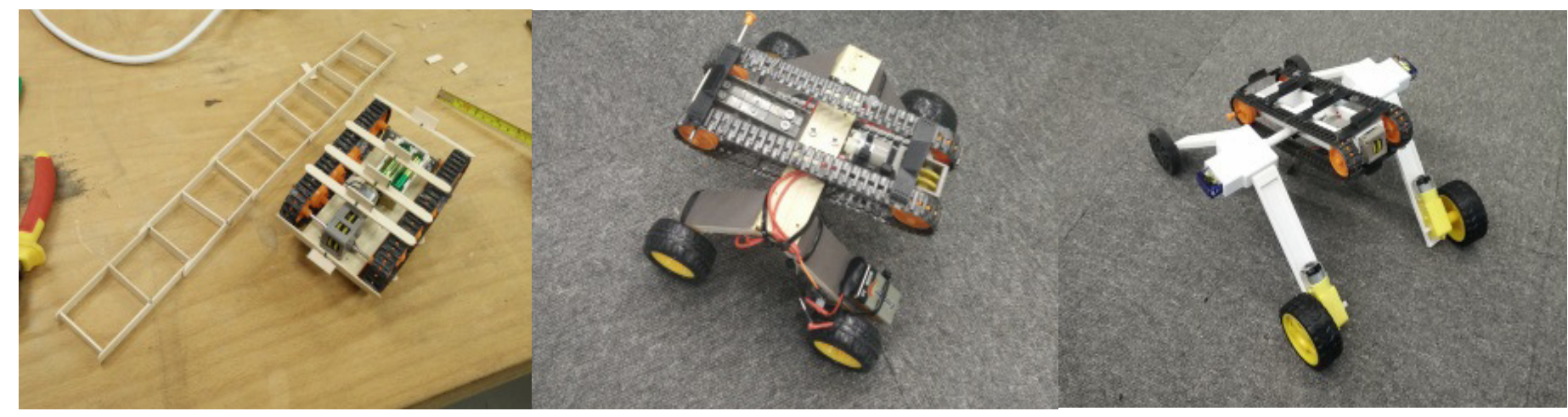

Figure 7 - Design Progression for the Climbing Robot 


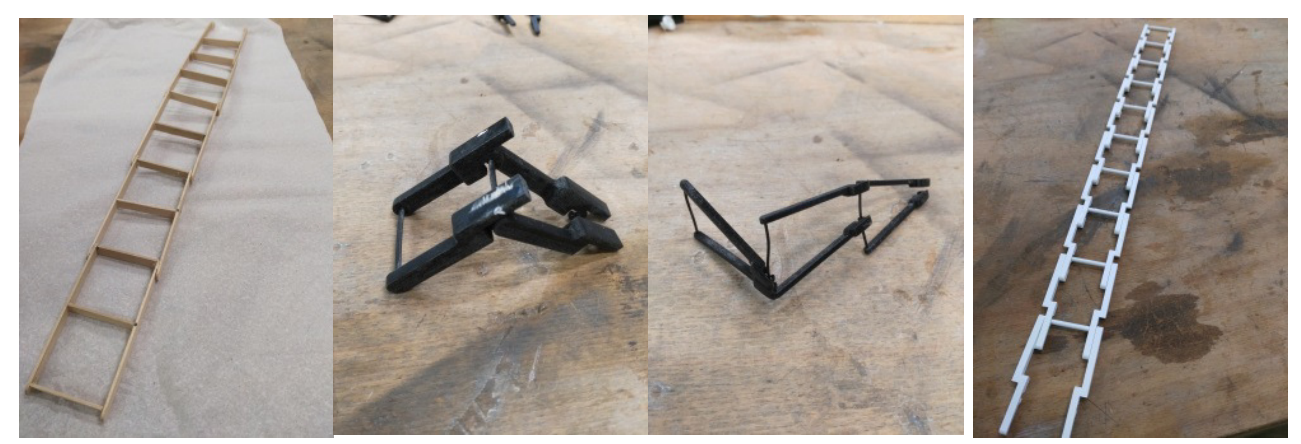

Figure 8 - Design Progression of the Ladder Prototypes

\subsection{Prototype \#2 - Dart and Adhesion Systems}

The second prototype involved the idea of launching a projectile coated in an adhesive towards the wall or ceiling with a line attached to it. After the adhesive hardened, the robot could winch itself up the wall toward the dart. There were three different primary methods pursued for attachment. The first method was with the adhesive on the tip of the dart and the string on the back (Figure $9-1^{\text {st }}$ schematic). This worked well due to its simplicity but was found lacking because of the inability to absorb impact (i.e. the dart bounces off the wall) and the fact that the string's mass and drag affected the flight of the dart. The second method attempted to overcome these flaws by having a detachable dart head that impacted the wall but the body of the dart detached from the head (Figure 9-2 schematic). The detachment of the body from the dart head changed the energy characteristics of the impact and increased the ability for the head to stick as opposed to bouncing off the wall. The string was wound around the dart body and unravels as the dart body fell toward the ground. This method decreased the effects of the string's drag during flight. The detachable head assisted in the absorption and redirection of the forces. The primary problem observed in this dart/string design is that the head did not consistently detach from the body at the right time. This prototype was successful in that, when the dart hit properly, the head would stick and the body would detach and unwind the string to the ground. The final method focused on using some of the glues' creeping problem to assist in the dart adherence. This design had a very sticky glue at the tip that helped absorb the impact. This particular sticky glue would creep, causing the dart body to rotate from being approximately orthogonal to the wall at initial impact to having the body parallel to the wall and contacting the wall. The sides of the dart were glue-covered so that when they contact the wall, they adhered (Figure $9-3^{\text {rd }}$ schematic). 

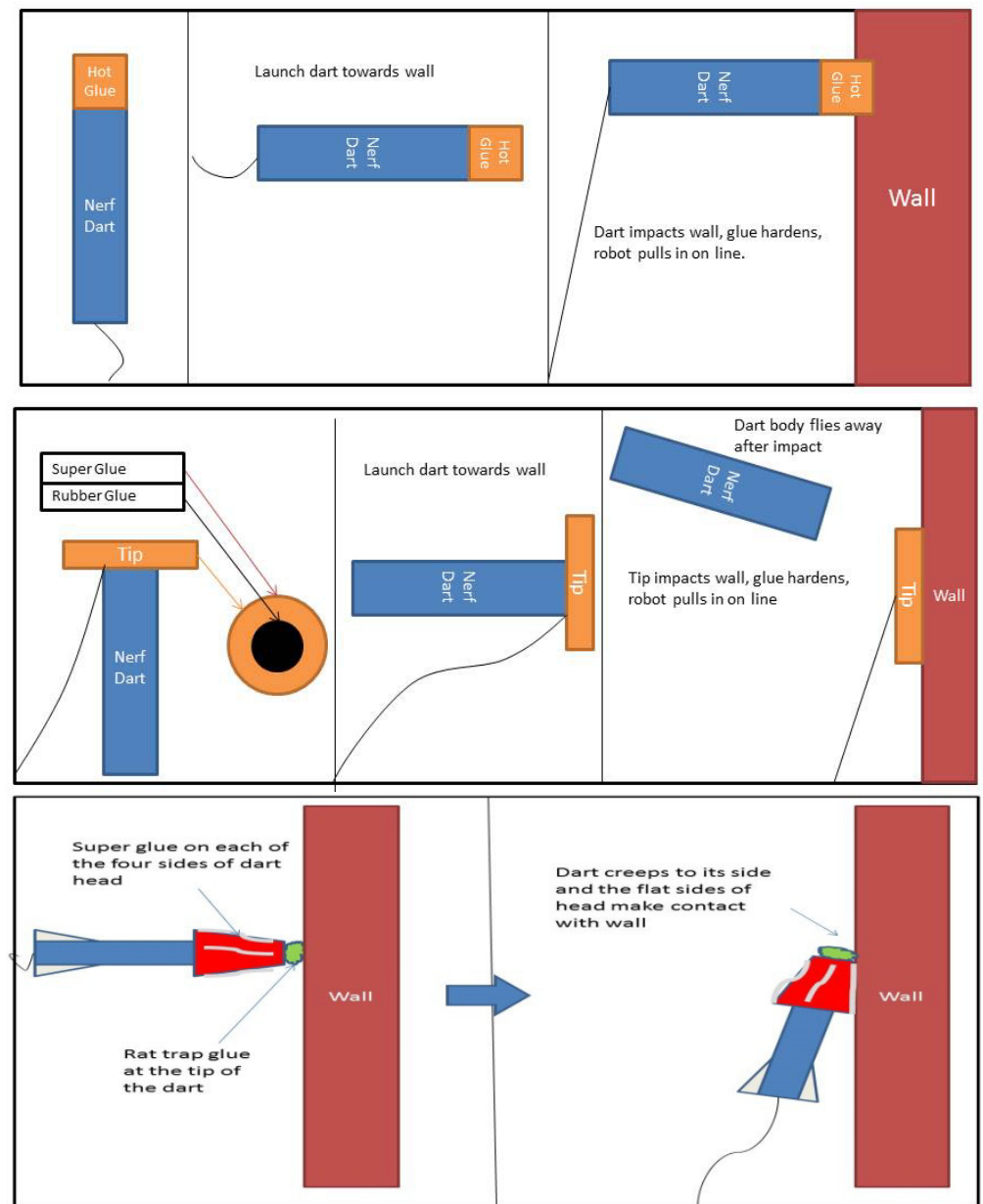

Figure 9 - Three Dart Adherence Prototypes

The choice of adhesives for the dart tip and the dart body was important to the prototype's functioning. Figure 10 shows some of the options. A wide variety of different adhesives are evaluated below in Table 1. As can be seen from the table, there are advantages and disadvantages for each choice.

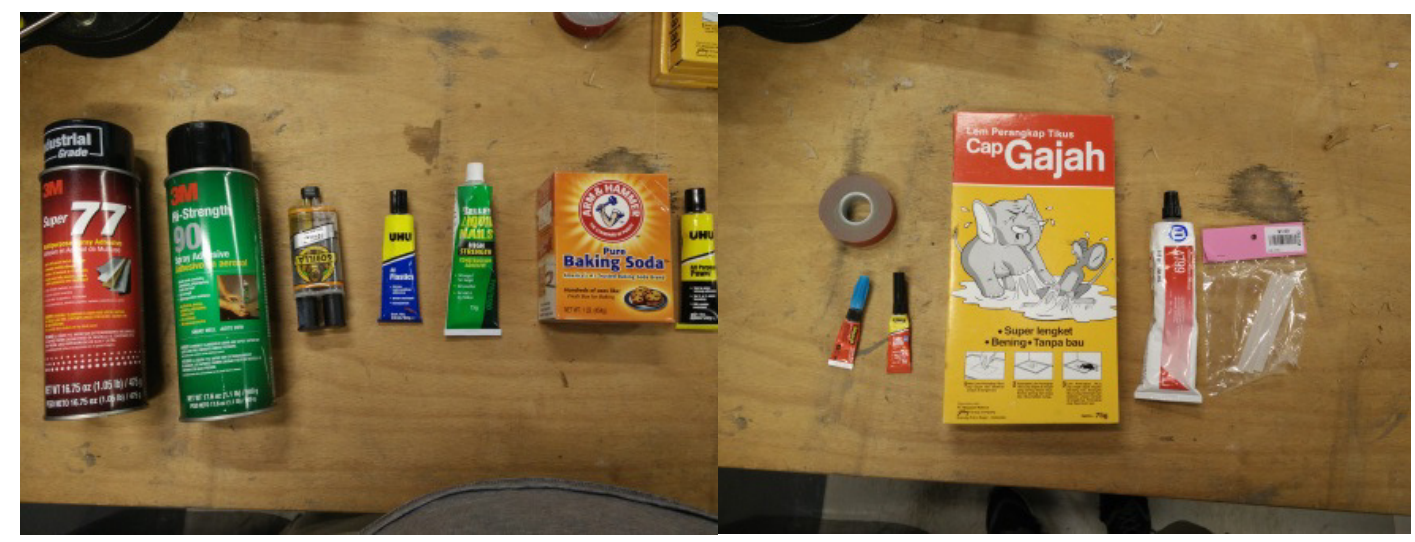

Figure 10 - Options for Adhesives 
Table 1 - Selection of Adhesives Used During Testing

\begin{tabular}{|c|c|c|}
\hline \multicolumn{3}{|c|}{ Comparison of a Variety of Adhesives } \\
\hline Brand (Chemical) & Pros & Cons \\
\hline $\begin{array}{l}\text { Selleys Liquid Nails High } \\
\text { Strength Construction } \\
\text { Adhesive }\end{array}$ & -Industrial strength & $\begin{array}{l}\text {-Lack of tackiness on impact } \\
-24 \text { hour set time } \\
\text {-Low range of applicable } \\
\text { materials }\end{array}$ \\
\hline Gorilla 5-Minute Epoxy & $\begin{array}{l}\text {-High strength } \\
\text {-Attaches to many surfaces } \\
\text {-Lots of existing research } \\
\text {-Forms to surface } \\
\text { irregularities }\end{array}$ & $\begin{array}{l}\text {-5-10 minute hardening time. } \\
\text {-Requires mixing } \\
\text {-Does not adhere to some } \\
\text { plastics } \\
\text {-No initial tackiness }\end{array}$ \\
\hline $\begin{array}{l}\text { 3M Super } 77 \text { Multipurpose } \\
\text { Spray Adhesive }\end{array}$ & $\begin{array}{l}\text {-Able to bond a wide range of } \\
\text { materials } \\
\text {-Set time } 10 \text { seconds to } 15 \\
\text { minutes }\end{array}$ & $\begin{array}{l}\text {-Difficult to apply } \\
\text {-Both surfaces need to sprayed }\end{array}$ \\
\hline $\begin{array}{l}\text { 3M Hi-Strength } 90 \text { Spray } \\
\text { Adhesive }\end{array}$ & $\begin{array}{l}\text {-Able to bond a wide range of } \\
\text { materials } \\
\text {-High strength and } \\
\text { temperature resistance }\end{array}$ & $\begin{array}{l}\text {-Difficult to apply } \\
\text {-Set time of } 1 \text { to } 10 \text { minutes } \\
\text {-Both surfaces need to be } \\
\text { sprayed }\end{array}$ \\
\hline Rat Trap Glue & $\begin{array}{l}\text {-Strong adhesive force } \\
\text {-Adheres to many surfaces } \\
\text {-Resists ricocheting on surface } \\
\text {-Sticks at steep impact angle }\end{array}$ & $\begin{array}{l}\text {-Large amount of creep } \\
\text {-Messy and hard to apply }\end{array}$ \\
\hline $\begin{array}{l}\text { 3M Industrial Rubber } \\
\text { Adhesive } 4799\end{array}$ & $\begin{array}{l}\text {-Acceptable tackiness on } \\
\text { impact } \\
\text {-Absorbs impact energy }\end{array}$ & $\begin{array}{l}\text {-Difficult to apply due to } \\
\text { blobs being dispensed } \\
\text {-Highly flammable } \\
\text {-Leaves black residue }\end{array}$ \\
\hline $\begin{array}{l}\text { UHU Super Glue Gel } \\
\text { (Cyanoacrylate) }\end{array}$ & $\begin{array}{l}\text {-Quick curing when properly } \\
\text { applied } \\
\text {-Strongest per unit area } \\
\text {-Lots of existing research } \\
\text {-Adheres well to flat concrete, } \\
\text { wood, paint, and metal }\end{array}$ & $\begin{array}{l}\text {-Required close proximity } \\
\text {-Disturbance vastly decreased } \\
\text { strength } \\
\text {-Did not stick well to many } \\
\text { plastics }\end{array}$ \\
\hline $\begin{array}{l}\text { Scotch Super Glue } \\
\text { (Cyanoacrylate) }\end{array}$ & $\begin{array}{l}\text {-Stronger than Gel } \\
\text {-Cured faster than Gel } \\
\text {-Did worse on more } \\
\text { porous/rough surfaces }\end{array}$ & $\begin{array}{l}\text {-Required even closer } \\
\text { proximity } \\
\text {-Tended to run on surfaces } \\
\text {-Little instant strength }\end{array}$ \\
\hline Hot Glue (Melted Silicone) & $\begin{array}{l}\text {-Strong } \\
\text {-Dried quickly } \\
\text {-Worked on most surfaces } \\
\text {-Consistent results }\end{array}$ & $\begin{array}{l}\text {-Required heating element } \\
\text {-Used more per mass than } \\
\text { some other solutions }\end{array}$ \\
\hline
\end{tabular}




\begin{tabular}{|l|l|l|}
\hline & -Adhesive upon impact & \\
-Spread to match surface & -Did not rebound & \\
-Easily cleaned & \\
\hline
\end{tabular}

In addition, design of the dart plays a big role in the functioning of the system. As with the adhesive, numerous options were explored. Figure 11 shows a number of the dart options. Table 2 lists advantages and disadvantages of different dart concepts.

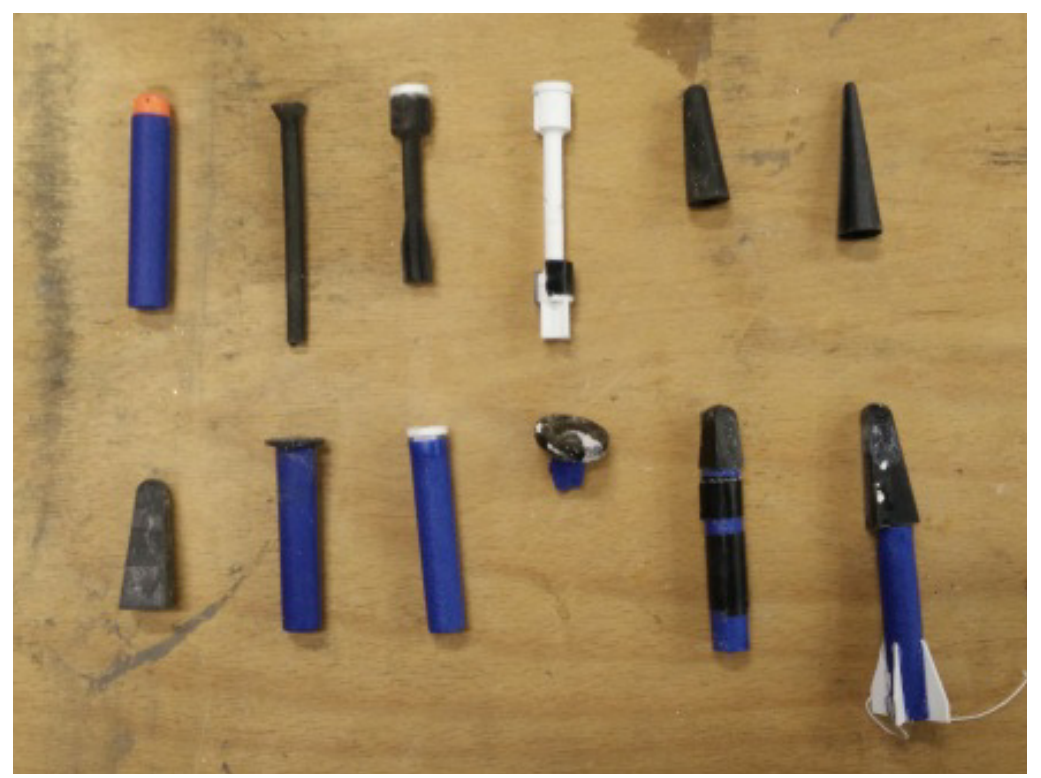

Figure 11 - Some Options for Dart Configurations

Table 2 - Comparison of Dart Concepts

\begin{tabular}{|c|c|c|c|}
\hline Dart & Method of Use & Pros & Cons \\
\hline & $\begin{array}{l}\text {-Adhesive placed on tip } \\
\text {-Separating tip from foam shaft } \\
\text { to redirect impact energy } \\
\text {-Stuffing tip with hot glue to } \\
\text { replace contact surface }\end{array}$ & $\begin{array}{l}\text {-Lightweight } \\
\text {-Easy launching } \\
\text { mechanism in NERF } \\
\text { Blaster }\end{array}$ & $\begin{array}{l}\text {-Plastic tip and foam } \\
\text { body difficult to } \\
\text { adhere most adhesives } \\
\text { to anything }\end{array}$ \\
\hline & -Too poor launch results to test & $\begin{array}{l}\text {-Lightweight and } \\
\text { flexible material } \\
\text { allowed more contact } \\
\text { area }\end{array}$ & $\begin{array}{l}\text {-3D printing of thin } \\
\text { material caused tears } \\
\text { during cleanup } \\
\text { process } \\
\text {-Too flimsy to launch }\end{array}$ \\
\hline & $\begin{array}{l}\text {-Dart head was designed to stick } \\
\text { as body fell off }\end{array}$ & $\begin{array}{l}\text {-Impact energy was } \\
\text { dispersed well } \\
\text { - Dart body could be } \\
\text { reused } \\
\text {-Flew consistent with }\end{array}$ & $\begin{array}{l}\text {-Dart head would } \\
\text { occasionally separate } \\
\text { midflight }\end{array}$ \\
\hline
\end{tabular}




\begin{tabular}{|c|c|c|c|}
\hline & & a lot of speed & \\
\hline & $\begin{array}{l}\text {-Dart body was designed to hold } \\
\text { thread internally and externally } \\
\text { while the head stuck to unroll } \\
\text { after impact }\end{array}$ & $\begin{array}{l}\text {-Thread did not affect } \\
\text { aerodynamics during } \\
\text { flight }\end{array}$ & $\begin{array}{l}\text {-Too many parts } \\
\text {-Thread would jerk } \\
\text { head off the wall }\end{array}$ \\
\hline & $\begin{array}{l}\text {-Round profile with head of dart } \\
\text { meant to have "tacky" adhesive } \\
\text { in order to stick } \\
\text {-After sticking, the dart would } \\
\text { fall towards the wall and the } \\
\text { instant adhesive would then } \\
\text { make contact with the wall }\end{array}$ & $\begin{array}{l}\text {-Good separation of } \\
\text { adhesives } \\
\text {-Internally launched } \\
\text { better for packaging }\end{array}$ & $\begin{array}{l}\text {-Needs close to ideal } \\
\text { situation for instant } \\
\text { adhesives on side to } \\
\text { work } \\
\text {-Unstable flight }\end{array}$ \\
\hline & -Same as above & -Lightweight & -Point was too sharp \\
\hline & $\begin{array}{l}\text {-Rat Trap Glue on top section } \\
\text {-Super glue on sides } \\
\text {-Dart would hit tip first and then } \\
\text { creep to make the long flat sides } \\
\text { have more contact }\end{array}$ & $\begin{array}{l}\text {-Aligned in } 1 \text { of } 4 \\
\text { ways } \\
\text {-More surface area for } \\
\text { super glue } \\
\text {-Aligned forces closer } \\
\text { to the wall }\end{array}$ & $\begin{array}{l}\text {-Aerodynamically } \\
\text { unstable } \\
\text {-glue needed to be on } \\
\text { all sides }\end{array}$ \\
\hline & $\begin{array}{l}\text {-Modified NERF dart that had a } \\
\text { larger surface area to allow more } \\
\text { contact. Tacky on the outer sides } \\
\text { of the tip and instant adhesive in } \\
\text { the middle of the tip }\end{array}$ & $\begin{array}{l}\text {-Surface area } \\
\text { improved strength of } \\
\text { adhesives } \\
\text {-Light and could be } \\
\text { shot from nerf gun }\end{array}$ & $\begin{array}{l}\text {-Not enough power to } \\
\text { fly far } \\
\text {-Lots of drag from the } \\
\text { tip }\end{array}$ \\
\hline & $\begin{array}{l}\text {-Adhesive on the tip } \\
\text {-Tip would be connected directly } \\
\text { to the string to minimize } \\
\text { moment arm } \\
\text {-Tip would impact and the body } \\
\text { would bounce away }\end{array}$ & $\begin{array}{l}\text {-Discrete } \\
\text {-Farther flight }\end{array}$ & $\begin{array}{l}\text {-Small surface area to } \\
\text { hold adhesives } \\
\text {-Small surface area to } \\
\text { attach adhesives }\end{array}$ \\
\hline & $\begin{array}{l}\text {-Bigger tip than the previous two } \\
\text { designs } \\
\text {-Could hold more tacky adhesive } \\
\text { and strong adhesive }\end{array}$ & $\begin{array}{l}\text {-Could hit at extreme } \\
\text { angles } \\
\text {-Large surface area } \\
\text { greatly increased } \\
\text { strength }\end{array}$ & $\begin{array}{l}\text {-Poor distance due to } \\
\text { drag and weight }\end{array}$ \\
\hline & $\begin{array}{l}\text {-Stable version of the square dart } \\
\text {-Stable from the increased length } \\
\text { at minimal weight due to the nerf }\end{array}$ & $\begin{array}{l}\text {-All of the advantages } \\
\text { of the square dart } \\
\text {-Lighter }\end{array}$ & $\begin{array}{l}\text {-Longer } \\
\text {-Shorter flight }\end{array}$ \\
\hline
\end{tabular}




\begin{tabular}{|l|l|l|l|}
\hline & dart body & -Stable & \\
\hline - & $\begin{array}{l}\text {-Purely focused on deciding if } \\
\text { the square dart idea would work } \\
\text { if stable }\end{array}$ & $\begin{array}{l}\text {-Dynamically stable } \\
\text { when thrown } \\
\text {-Added length helped } \\
\text { create a tighter seal } \\
\text { for the super glue }\end{array}$ & $\begin{array}{l}\text {-Large } \\
\text {-Needed to be hand } \\
\text { thrown }\end{array}$ \\
& & \\
\hline
\end{tabular}

Of all the different combinations of darts and adhesives, success was most probable when there was a relatively large surface area and/or the impact energy was dispersed. Based on numerous tests, the flat-sided dart is recommended (Fig 12). The stability of the flight allowed the dart to continuously hit tip first where the "Rat Trap Adhesive" or "Hot Glue" was placed. It would then fall onto its side and the adhesive on the side of the dart (super glue) engaged with the wall.

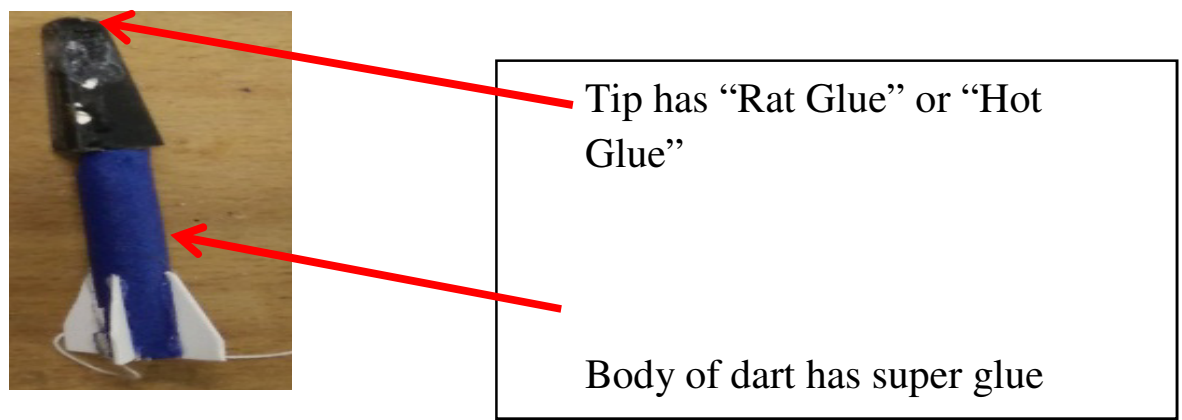

Figure 12 - First Preferred Embodiment for Dart and Adhesives

During testing, the amount of mass held by the dart was measured at $1.2 \mathrm{~kg}$. It should be noted that it failed where the thread attached to the dart. The mass held by the dart could be drastically improved if the fastening method was improved.

Another recommended design is the large tipped nerf dart (Fig. 13). In this embodiment, both rubber adhesive and super glue gel were applied to the tip of the dart. The rubber adhesive was in the center and super glue the gel formed a ring around it. The dart stuck very well on contact with only slight separation towards the top of the tip. The center rubber adhesive forms the initial bond with the wall. The super glue gel was allowed to set for 5 minutes, and then the strength of the bond was measured. This dart was capable of holding $8 \mathrm{~kg}$.

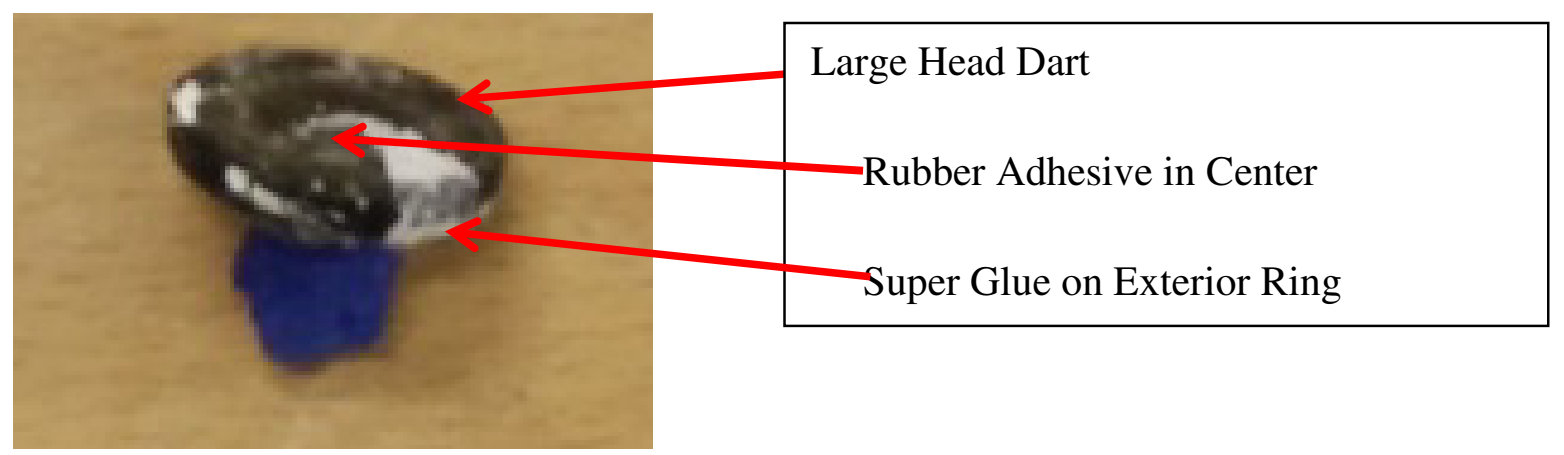

Figure 13 - Second Preferred Embodiment for Dart and Adhesives 
A third option that worked extremely well was a dart with hot glue at the tip. Due to the light body, the dart would stick on impact with little issue. The hot glue would harden quickly and could stick to almost any surface. In addition, the bond created was typically enough to hold $4 \mathrm{~kg}$ before experiencing serious creep. This option is embodied in Prototype \#3 and described in detail below.

The overall best adhesive based on strength, ability to set on many materials, and set time was the hot glue. The primary problem with hot glue is that a heating element would need to be included that could possibly damage the internals of the robot and would require a significant amount of energy. However, the complexity most likely would not be much greater than creating a system for applying any other adhesive.

Note that the focus of this prototype was the different combinations of dart configurations and adhesives. However, a climbing device was also created and successfully tested. Figure 14 shows this device partially through a successful climb.

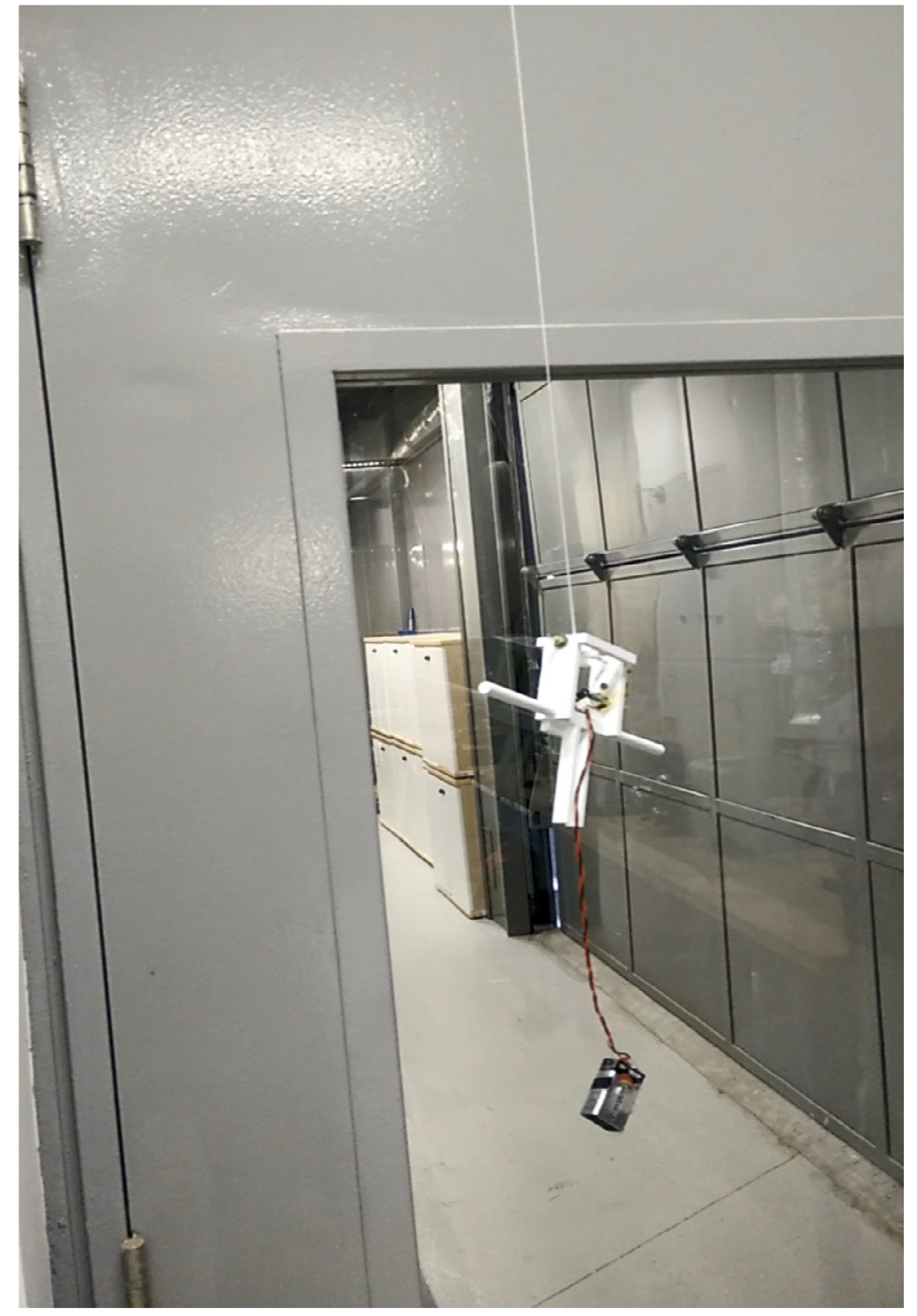

Figure 14 - Functioning Climbing Device 


\subsection{Refined Prototype \#2 - Full System: Climbing Robot / Dart / Tether / Adhesion Systems}

Refined prototype \#2 is a full system for climbing that includes a remotely driven climbing robot that remotely activates shooting a sticky dart that adheres to a wall and deploys a tether mechanically connecting the robot to the wall. The robot uses a winching system to climb the wall to the dart. Detailed description of the options for components as well as the final choice for each subsystem is provided below.

Options for the chassis are shown below in Figure 15. Five different options are considered. The "Parrot Jumping Sumo" is chosen based on availability, functionality and available camera along with autonomous and semiautonomous modes. Weight of the chassis is $11.5 \mathrm{oz}$.

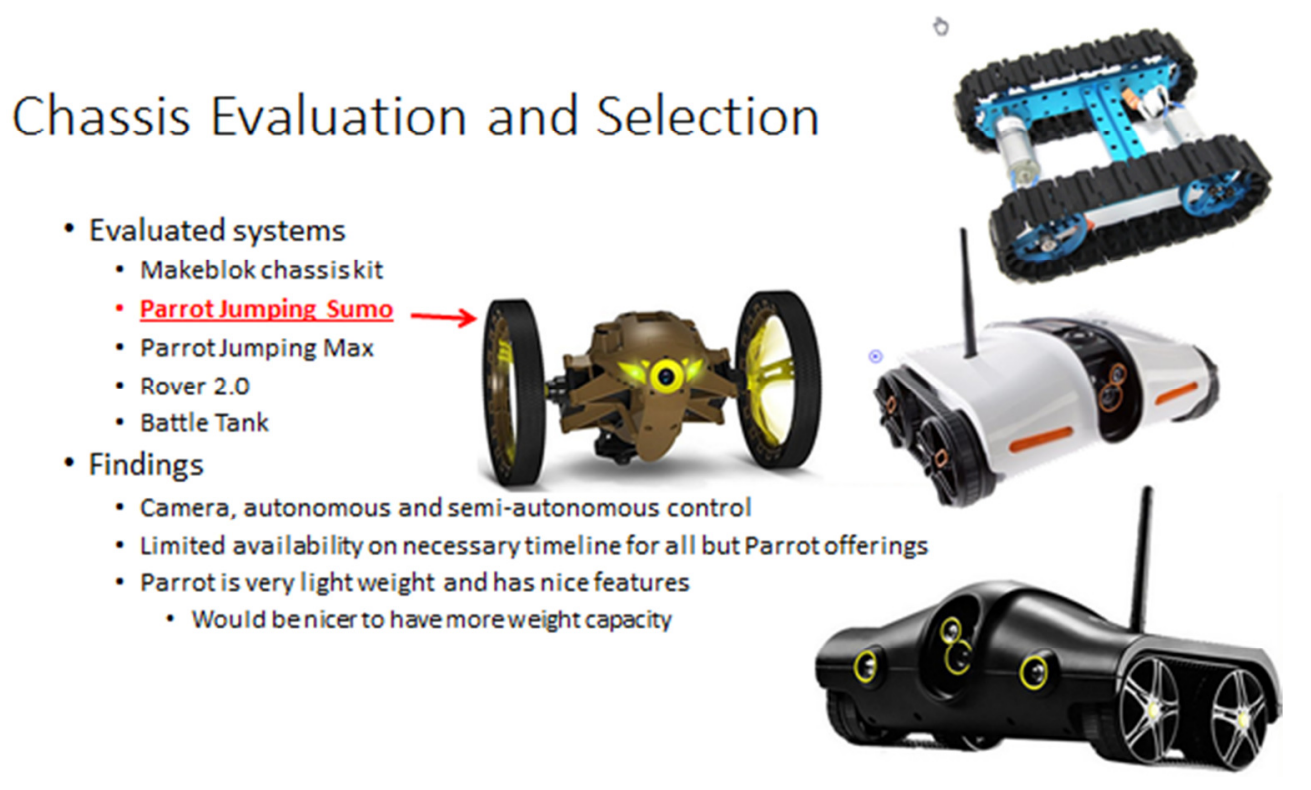

Figure 15 - Chassis Selection - Parrot Jumping Sumo

Options for the Dart Launcher system are shown below in Figure 16. Three different options are considered. A modified version of the "Nerf Mega Blaster" is chosen because it balances weight, projectile energy and size.

\section{Component Evaluation and Selection}

- Gun/launcher

- Evaluated Devices

- Cable Caster

- Nerf Jolt

- Nerf Mega Blaster

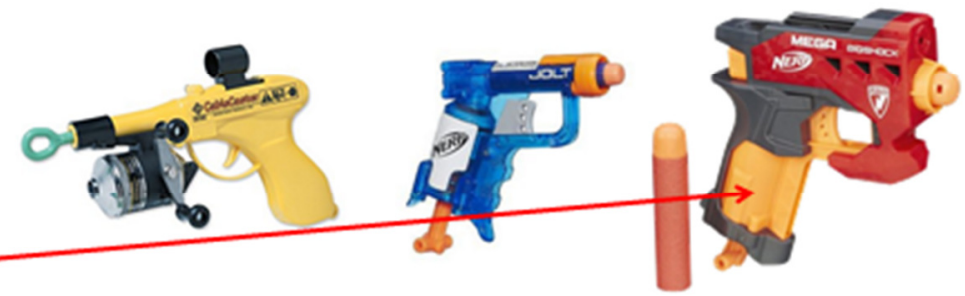

- Findings

- The cable caster system was too heavy with its steel barrel and high energy propulsion for the Parrot drone chassis

- The Nerf Jolt was the lightest weight of all the systems, initially the dart weight seemed insufficient to carry the tether

- The stripped down Nerf Mega Blaster was a good balance between system weight, projectile energy and size

Figure 16 - Dart Launch Selection - Modified Nerf Mega Blaster 
Options for the adhesive are shown below in Figure 17. Three different options are considered. The "Hot Glue" is chosen based on its superior adhesive properties as long as the temperature is closely controlled. Note that this choice corresponds with the extensive research done as documented in the description of prototype \#2 above. The temperature control system is described in detail below.

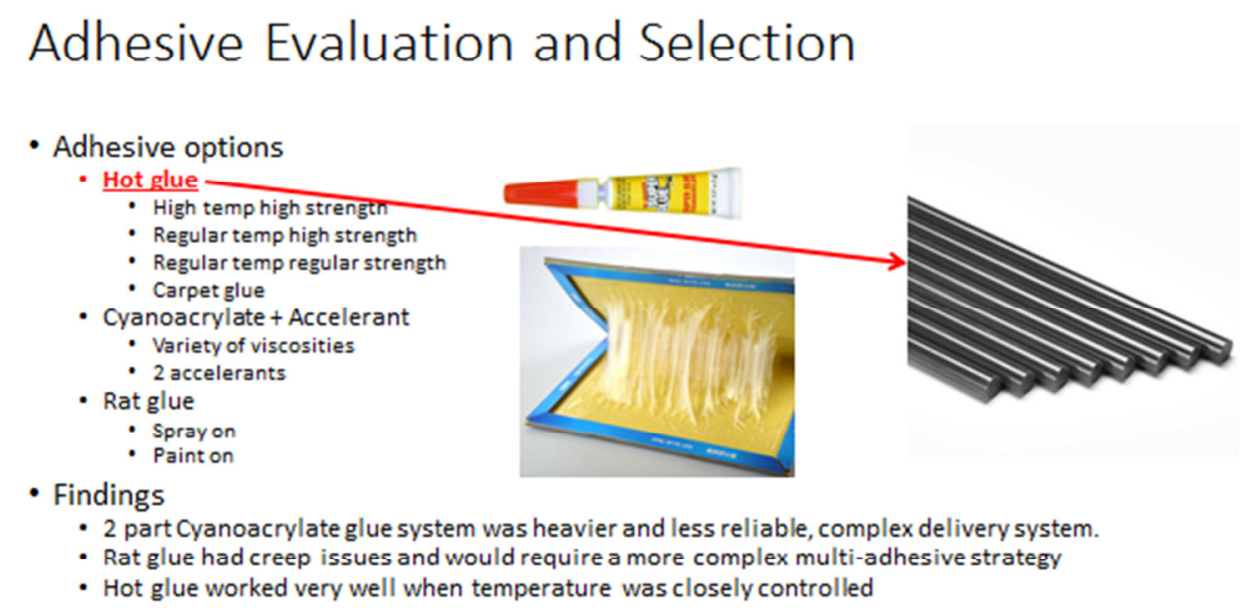

Figure 17 - Adhesive Selection - Hot Glue

Options for the winch and line (tether) are shown below in Figure 18. Two different line options and three different winch options are considered. The "Braided line" is chosen based on its strength and weight. The COTS motor and gear box with a 3-D printed custom spool is chosen as it has a fantastic gear ratio (based on a epicycle gear system) and is light weight and powerful.

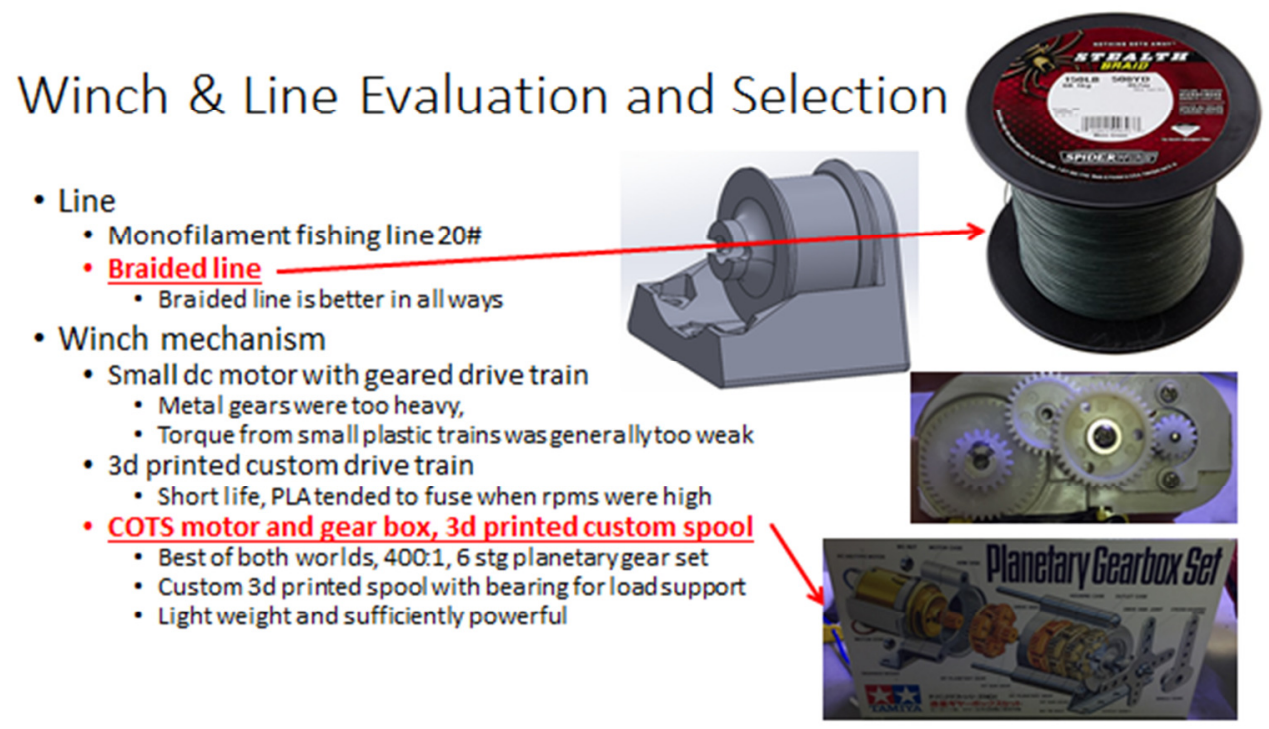

Figure 18 - Winch \& Line Selection - Braided Line \& COTS Planetary Gear Box

The control system for the chassis is done from a DGI-based control system, which can work on a phone or tablet. An iPhone was used for control in this case. This controls the velocity and direction of the robot. The remaining items that need control are the heating of the hot glue, the launching of the dart and the on/off for the winch. All 
these are controlled using simple on/off relay with a 4-channel RF relay board running at $433 \mathrm{MHz}$. Summary of these controls are shown in Figure 19 below. The iPhone control interface is shown in Figure 20. The details of the relay layout are shown in Figure 24.

\section{Controls Specification}

\section{- Controls}

- COTS chassis system handles video and directional control through app on phone or tablet

- Simple on/off relay requirements

- Dart hot glue pre-heat

- Dart launch

- Winch on/off

- Small 4channel RF relay board met the need

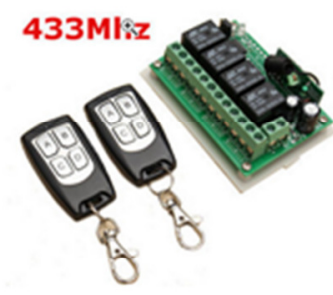

\section{Figure 19 - Controls Specification for Chassis, Heat, Launch and Winch}

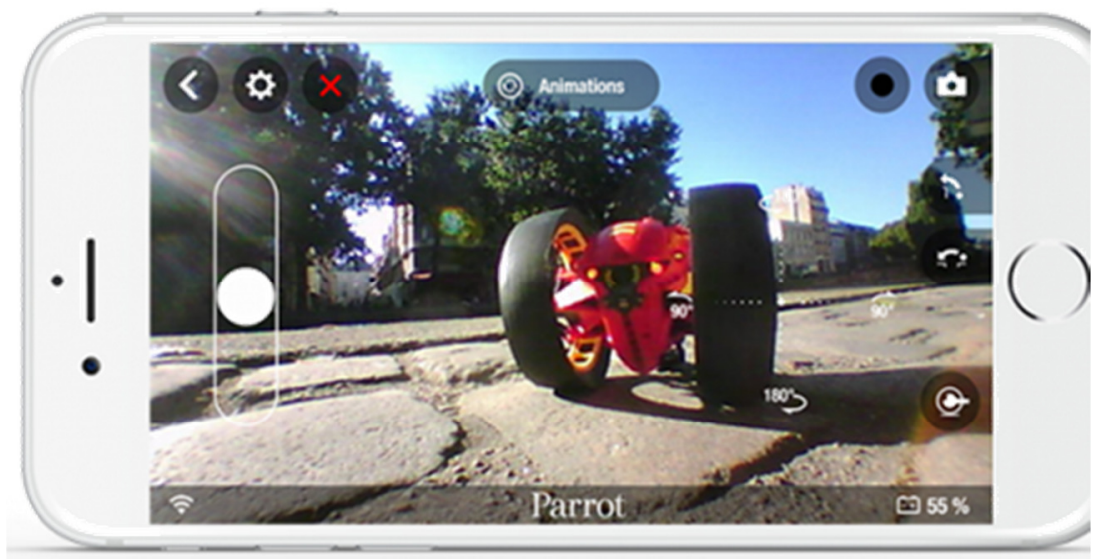

Figure 20 - IPhone Control Interface for Parrot Robot

Details for the dart design are shown in Figure 21. The tip of the dart has a 1" $\mathrm{x}$ 1" piece of Printed Circuit Board (PCB) attached to it. A 1/32 inch diameter NiCr wire is coiled along the PCB and then runs down the sides of the dart. Current can be run through the wire producing heat from the resistance. A layer of hot glue is deposited on top of the wire that is sitting on the PCB. The braided tether or line is wound inside the body of the dart and deploys as the dart is projected toward the wall. 


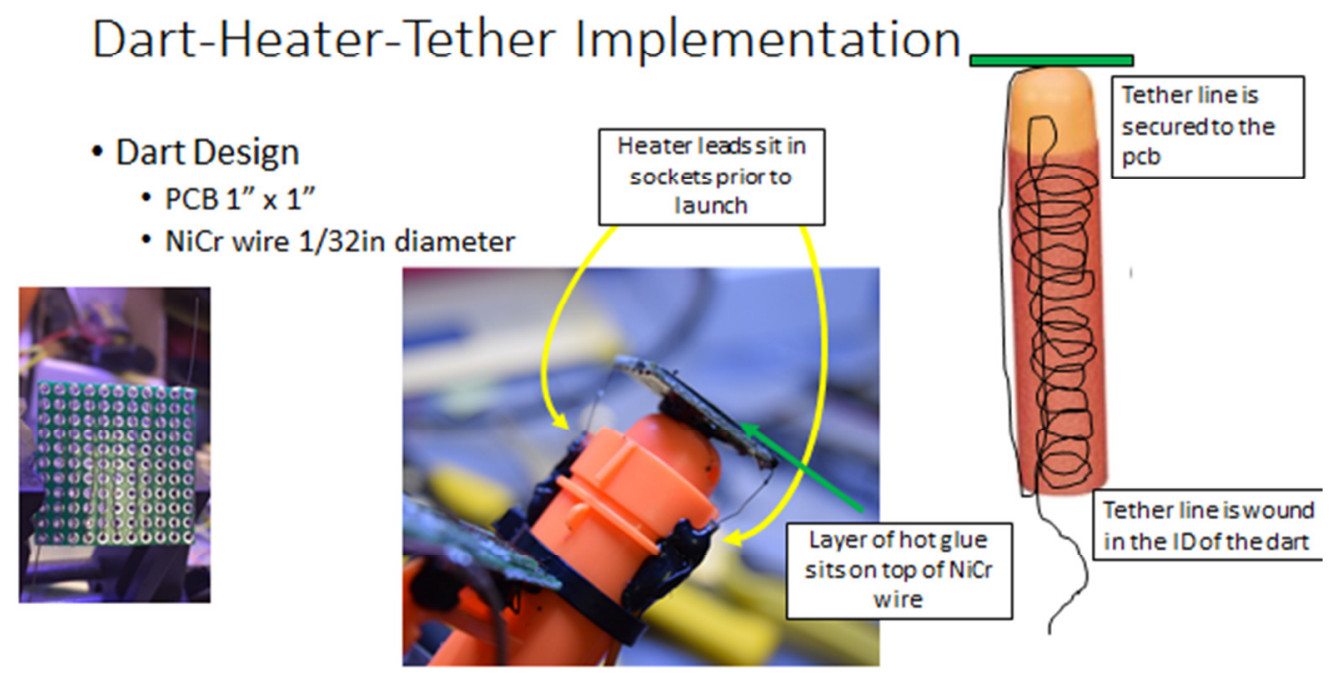

Figure 21 - Details for Dart-Heater-Tether System

The Heating and Trigger Launching system is further described in Figure 22. A small bungee cord is stretched over the launching trigger. The cord is held in place by a line that runs over the heating element on the PCB. When the seating element becomes sufficiently hot, (at which point the hot glue is ready to adhere on impact) the heat cuts the wire and the bungee pulls the trigger. The operational embodiment is shown in the figure below.

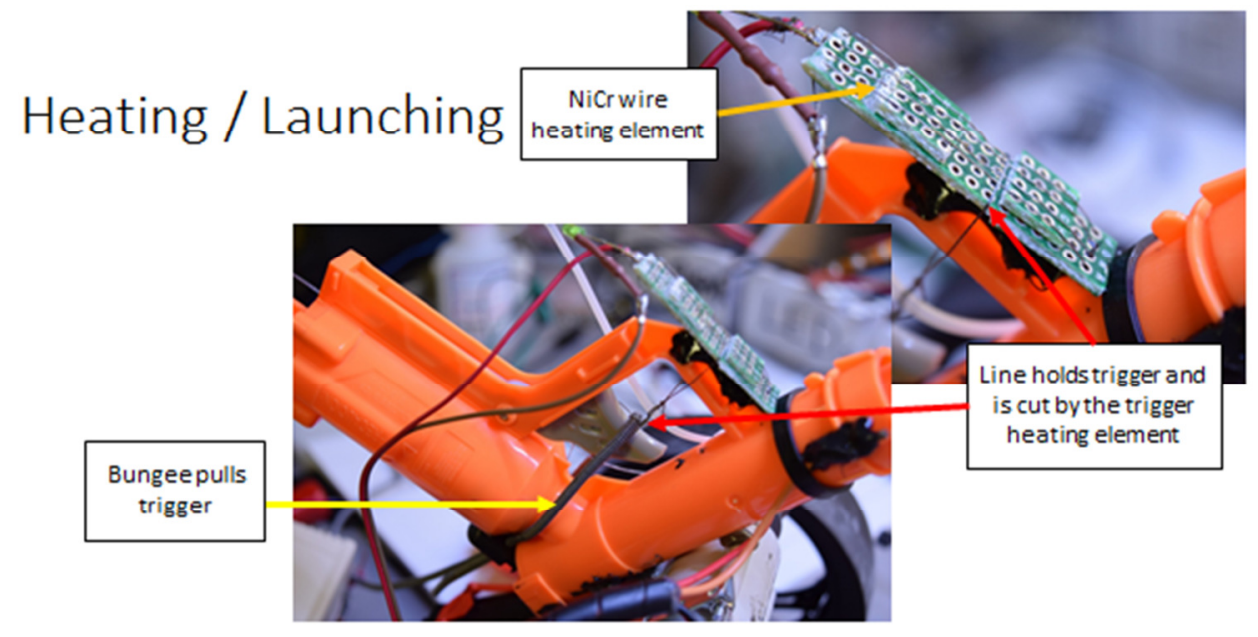

Figure 22 - Details for Heater-Trigger Launch System

System layout for the Winch System, including the motor, planetary gearbox and spool are shown in Figure 23. 


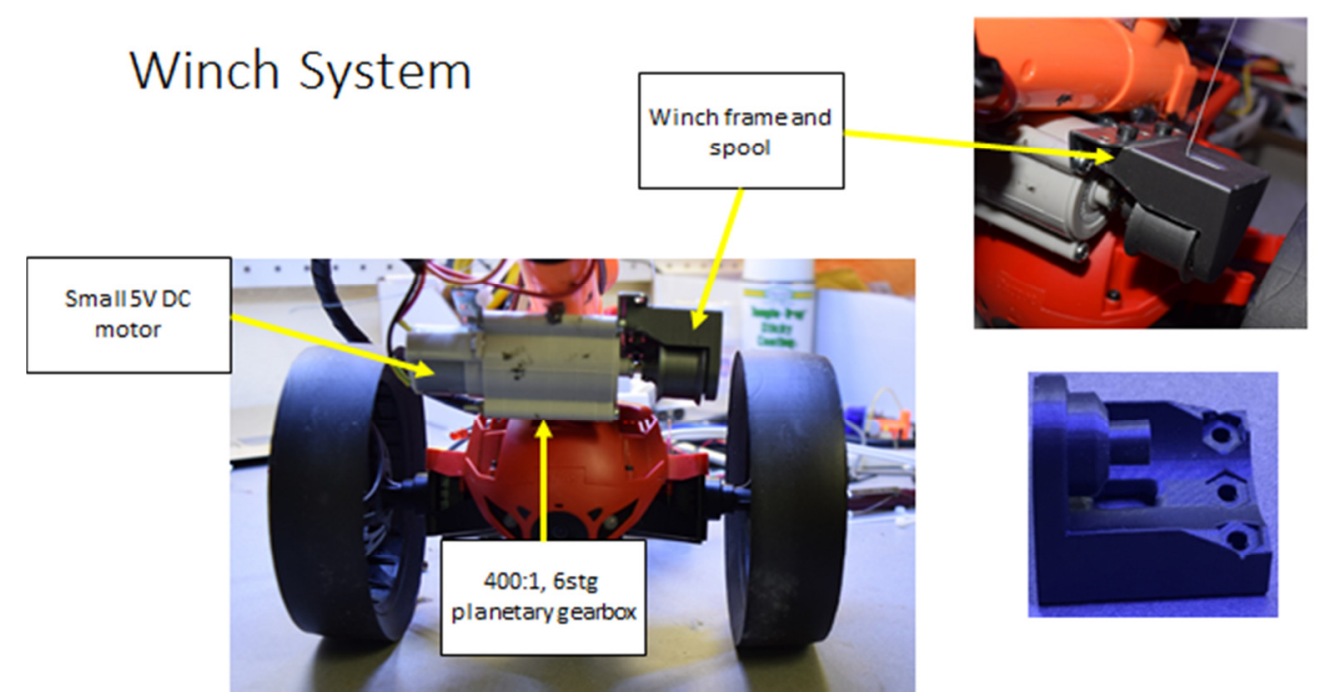

Figure 23 - System Layout for Winch System

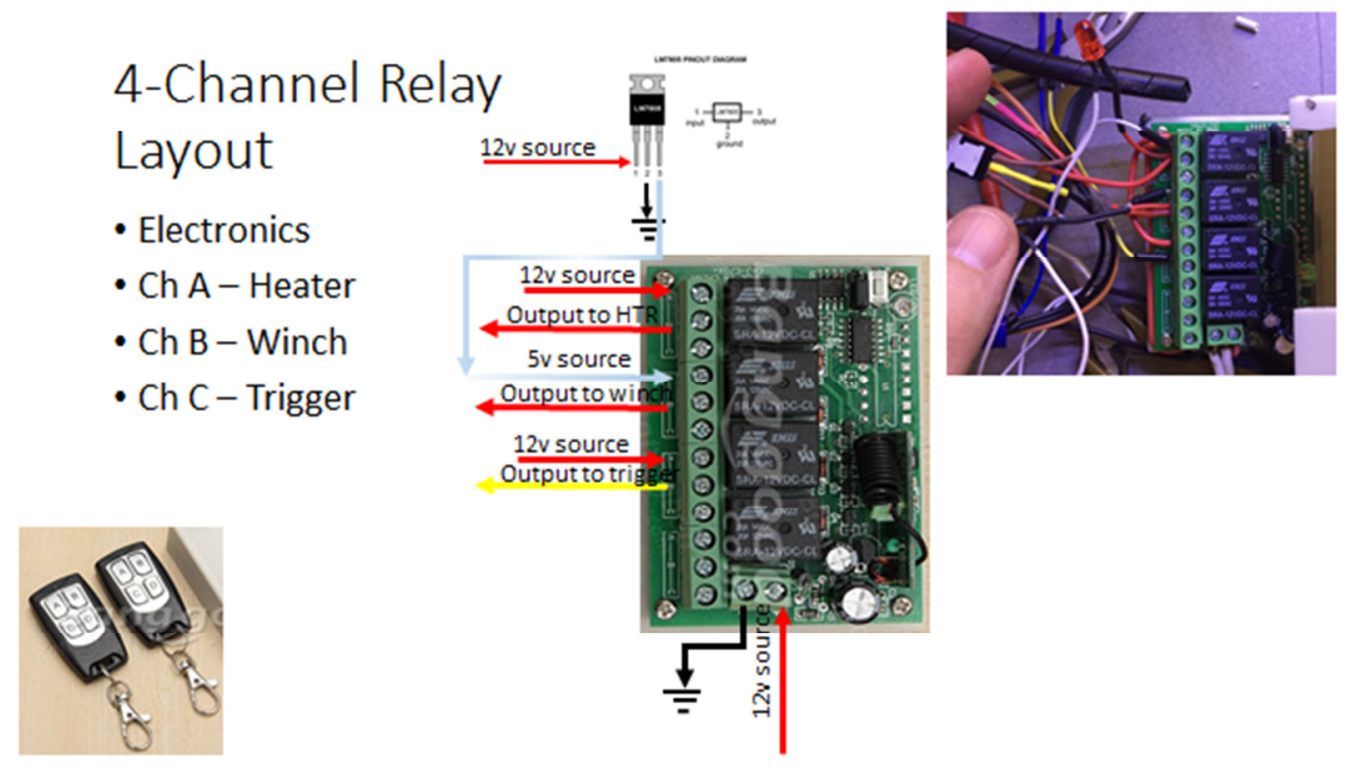

Figure 24 - System Layout for 4-Channel Relay System

This prototype has successfully completed the full operation consisting of:

- movement to a location close to a wall

- stopping at a proper distance for the dart shot

- heating the glue on the dart's tip to proper temperature

- firing the dart

- $\quad$ proper tether deployment during dart flight

- achieving good dart/wall adhesion

- using the dart as the wall anchor for the tether

- $\quad$ using the winch to pull the system up to the dart's location

\section{CONCLUSION}

This paper documents work to develop and assess design methods to assist in design of wall-climbing systems. Specifically, mind map-based systems that enhance the use of biological analogies and assist in implementation of 
additive manufacturing methods are documented. Two prototypes for novel wall-climbing systems are created with the assistance of the design methods. The wall-climbing systems are described in sufficient detail to allow for recreation of the products. Initial assessment of the mind maps indicates that they definitely add value to the ideation process.

\section{REFERENCES}

1. White, Christina, Kristin Wood, and Dan Jensen. "From brainstorming to C-sketch to principles of historical innovators: ideation techniques to enhance student creativity." Journal of STEM Education: Innovations and Research 13.5, \#12 for 2012.

2. Davies, Martin, "Concept mapping, mind mapping and argument mapping: what are the differences and do they matter?" Higher Education, Springer Netherlands, New York, Vol. 62, 279-301, 2010.

3. Anderson, M., Onyechi, J., Yamazaki, T., Wood, K., Jensen, D., Mind Map for Biologically Inspired Covert Visual Systems: A pilot study, SW Regional ASEE Conference, Provo, UT, Sept. 2017.

4. Linsey, Julie S., K. L. Wood, and A. B. Markman. "Increasing innovation: presentation and evaluation of the wordtree designby-analogy method." ASME 2008 International Design Engineering Technical Conferences and Computers and Information in Engineering Conference. American Society of Mechanical Engineers, New York, 2008.

5. Helms, Michael, Swaroop S. Vattam, and Ashok K. Goel. "Biologically inspired design: process and products." Design studies Journal, Design Research Society, Vol 30.5, 606-622, 2009.

6. Zahedi, Mithra, and Lorna Heaton. "Mind Mapping as a Tool, as a Process, As a Problem/Solution Space." DS 83: Proceedings of the 18th International Conference on Engineering and Product Design Education (E\&PDE16), Design Education: Collaboration and Cross-Disciplinarity, Aalborg, Denmark, 8th-9th September 2016. 2016.

7. Marshall, S., R. Crawford, And D. Jensen, “Analogy Seeded Mind-Maps: A Comparison of Verbal and Pictorial Representation of Analogies in the Concept Generation Process”, ASME Intl. Design Engineering Technical Conference, Charlotte, NC, Aug, 2016.

8. Product Design, Techniques in Reverse Engineering and New Product Development, by Kevin Otto \& Kristin Wood, Prentice Hall, 2000.

9. Shark's Paintbrush: Biomimicry and How Nature is Inspiring Innovation, by Jay Harman, White Cloud Press, 2013.

10. Shah, J. J., N. Vargas-Hernandez, J.D. Summers, and S. Kulkarni, "Collaborative Sketching (C-Sketch) — An Idea Generation Technique for Engineering Design.” The Journal of Creative Behavior, Creative Education Foundation, Massachusets, Vol. 35, pg. 168-198, 2001.

11. Giffen, Deb, MCC, Director of Innovative Learning Solutions at Wharton Executive Education, https://executiveeducation. wharton.upenn.edu/ /media/wee/wharton\%20at\%20work/nano\%20tools\%20pdfs/1306\%20find\%20 in novation\%20success.pdf

12. Serrat, Olivier. "The SCAMPER technique." Knowledge Solutions, Asian Development Bank, Philippines, Vol. 31, pg. 1-4, 2009.

13. Mann, Darrell. "An introduction to TRIZ: The theory of inventive problem solving." Creativity and Innovation Management, Blackwell Publishers, Massachusetts, Vol. 10.2, pg. 123-125, 2001.

14. Rohrbach, Bernd. "Kreativ nach Regeln-Methode 635, eine neue Technik zum Lösen von Problemen." Absatzwirtschaft, pg. Vol. 12.19, 73-75, 1969.

15. Benyus, Janine, Biomimicry, William Morrow, New York, 1997.

16. Forbes, Peter, "The Gecko's Foot: Bio-inspiration, Engineering New Materials and Devices from Nature," W.W. Norton \& Company, New York, 2005.

17. Goel, Ashok K., Swaroop S. Vattam, and Michael E. Helms, "Biologically Inspired Design: Human Reasoning Using Nature's Experiences." IJCAI Workshop on Grand Challenges in Reasoning From Experience. 2009.

18. Helms, Michael, Swaroop S. Vattam, and Ashok K. Goel. "Biologically inspired design: process and products." Design studies Journal, Design Research Society, Vol 30.5, 606-622, 2009.

19. Mak, Teresa W., and Lily H. Shu. "Use of biological phenomena in design by analogy." ASME 2004 International Design Engineering Technical Conferences and Computers and Information in Engineering Conference. American Society of Mechanical Engineers, Utah, 2004.

20. McAdams, Daniel A., and Kristin L. Wood. "A quantitative similarity metric for design-by-analogy." Transactions-American Society of Mechanical Engineers Journal of Mechanical Design, The American Society of Mechanical Engineers, New York, Vol. 124.2, pg. 173-182, 2002. 
21. Zahedi, Mithra, and Lorna Heaton. "Mind Mapping as a Tool, as a Process, As a Problem/Solution Space." DS 83: Proceedings of the 18th International Conference on Engineering and Product Design Education (E\&PDE16), Design Education: Collaboration and Cross-Disciplinarity, Aalborg, Denmark, 8th-9th September 2016. 2016.

22. Shah, Jami J., and Noe Vargas-Hernandez. "Metrics for measuring ideation effectiveness." Design studies, Elsevier Science, Great Britian, Vol. 24.2, pg. 111-134, 2003.

23. Buzan, Tony, The Mind Map Book, Plumb Books, 1993.

24. K. Daltorio, S. Gorb, A. Peressadko, A. Horchler, T. Wei, R. Ritzmann, and R. Quinn, "Microstructured Polymer Adhesive Feet for Climbing Robots", MRS BULLETIN • Vol 32 • June • www/mrs.org/bulletin, 2007.

25. T. Bretl, S. Rock, J. Latombe, B. Kennedy, and H. Aghazarian, "Free-climbing with a multi-use robot", Experimental Robotics IX, Spring Tracts in Advanced Robotics (STAR), 2008.

26. H. Prahlad, R. Pelrine, S. Stanford, J. Marlow, and R. Kornblush, "Electroadhesive wall-climbing robots enabled by a novel, robust and electrically controllable adhesion technology," IEEE International Conference on Robotics and Automation, pp. 3028-3033, May 2008.

27. H. Yang, R. Liu, Q. Hong, and N. He, "A miniature multi-joint wall-climbing robot based on new vibration suction robotic foot," Proceedings of the IEEE International Conference on Automation and Logistics, Qingdao, China, pp. 1160- 1165, 2008.

28. M. Spenko, G. Haynes, J. Saunders, M. Cutkowsky, A. Rizzi, J. Full, and D. Koditschek, "Biologically inspired climbing with a hexapedal robot," Journal of Field Robotics, 2008.

29. K. Autumn, S. Hsieh, D. Dudek, J. Chen, and C. Chitaphan, “Dynamics of geckos running vertically," The Journal of Experimental Biology, 2006.

30. J. Dickson and J. Clark, "Design of a multi-modal climbing and gliding robotic platform," IEEE/ASME Transactions of Mechatronics, Vol. 18, Issue, 2, 2013.

31. Hwang Kim, Dongmok Kim, Hojoon Yang, Kyouhee Lee, et al. "Development of a wall-climbing robot using a tracked wheel mechanism," Journal of Mechanical Science and Technology, 2008.

32. D. Goldman, T. Chen, D. Dudek and R. Full, "Dynamics of rapid vertical climbing in cockroaches reveals a template," The Journal of Experimental Biology, 2006.

33. R. Full and D. Koditschek, "Templates and anchors: Neuromechanical hypotheses of legged locomotion on land," The Journal of Experimental Biology, 1999.

34. Giuk Lee, Junhwan Park, Hwang Kim, "Wall-climbing robots with track-wheel mechanism," 2011 3rd International Conference on Machine Learning and Computing (ICMLC), 2011.

35. Kellar, A., Full, R., Goldman, D., et. al., "Robotics in Scansorial Environments", Proceedings of SPIE - The International Society for Optical Engineering, Vol 5804, pgs 291-302, 2005.

36. Shah, J., Experimental Investigation of Progressive Idea Generation Techniques in Engineering Design, ASME 1998 International Design Engineering Technical Conferences and Computers and Information in Engineering Conference. American Society of Mechanical Engineers, Atlanta, GA, 1998.

37. Feldbaum, C. . Wordnet: An electronic lexical database. Cambridge, MA:, MIT Press. 1998.

38. Linsey, J., Wood, K., \& Markman, A., Increasing innovation: Presentation and evaluation of the WordTree design-by-analogy method. Proceedings of the ASME Design Theory and Methodology Conference,, New York, NY.2008. 